\title{
Youth in Substitute Care Presenting with Sexual Behavior Problems
}

Christopher Zaddach

Loyola University Chicago

Follow this and additional works at: https://ecommons.luc.edu/luc_theses

Part of the Clinical Psychology Commons

\section{Recommended Citation}

Zaddach, Christopher, "Youth in Substitute Care Presenting with Sexual Behavior Problems" (2010). Master's Theses. 497.

https://ecommons.luc.edu/luc_theses/497

This Thesis is brought to you for free and open access by the Theses and Dissertations at Loyola eCommons. It has been accepted for inclusion in Master's Theses by an authorized administrator of Loyola eCommons. For more information, please contact ecommons@luc.edu. (c) (i) $(9)$

This work is licensed under a Creative Commons Attribution-Noncommercial-No Derivative Works 3.0 License. Copyright (c) 2010 Christopher Zaddach 


\title{
LOYOLA UNIVERSITY CHICAGO
}

\section{YOUTH IN SUBSTITUTE CARE PRESENTING WITH SEXUAL BEHAVIOR PROBLEMS}

\author{
A THESIS SUBMITTED TO \\ THE FACULTY OF THE GRADUATE SCHOOL \\ IN CANDICACY FOR THE DEGREE OF \\ MASTER OF ARTS
}

PROGRAM IN CLINICAL PSYCHOLOGY

BY

CHRISTOPHER WERNER ZADDACH

CHICAGO, ILLINOIS

MAY 2011 
Copyright by Christopher Zaddach, 2011

All rights reserved 


\section{ACKNOWLEDGMENTS}

I would like to thank the individuals who directly and indirectly made this project possible: my faculty chair and research mentor, Dr. Scott Leon, and former clinical director of CAUSES, Dr. Steve Spacarelli. Without their support, including Dr. Spacarelli's contribution of time and data, this study would not have been possible. Thank you, Dr. Leon for your tireless support and encouragement throughout this invaluable learning process and development. I am also grateful for the support, feedback, and ideas from Dr. Maryse Richards. Her insight on the subject matter and interests undoubtedly improved the rigor and value of the study.

Finally, I would like to offer personal thanks to family and friends who provided the extensive emotional and moral support and encouragement throughout this process. 


\section{TABLE OF CONTENTS}

ACKNOWLEDGMENTS

LIST OF TABLES

LIST OF FIGURES viii

$\begin{array}{ll}\text { ABSTRACT } & \text { ix }\end{array}$

CHAPTER ONE: INTRODUCTION 1

CHAPTER TWO: REVIEW OF RELATED LITERATURE 4

Definition of Sexual Behavior Problems (SBP) in Youths 4

Incidence and Prevalence of Sexual Behavior Problems in Youths 6

Typical Sexual Behaviors across Ages $\quad 7$

Sexual Behavior Problems: Gender Differences $\quad 10$

Risk Factors Associated with Sexual Behavior Problems in Youths 12

Childhood Sexual Abuse $\quad 13$

Physical Abuse $\quad 15$

Family Characteristics 16

Exposure to Domestic Violence 16

Witnessing Community Violence 18

Theoretical Conceptualization $\quad 19$

$\begin{array}{ll}\text { Traumagenic Model } & 20\end{array}$

Moderating Variables: Posttraumatic Stress Symptoms (PTS) and

Sexual Concerns (SC) 24

Trauma Symptoms in Children with Sexual Behavior Problems 25

Trauma and Emotion Dysregulation $\quad 27$

Current Study $\quad 32$

Children with Sexual Behavior Problems in Substitute Care 32

Research on Children with Sexual Behavior Problems in Substitute Care 33

Study Hypotheses $\quad 34$

Main Effects $\quad 34$

Interaction Effects $\quad 34$

Gender Differences $\quad 38$

$\begin{array}{ll}\text { Mediation } & 38\end{array}$

$\begin{array}{ll}\text { Moderated-Mediation } & 38\end{array}$

Planned Analyses $\quad 39$

Hypothesis 1. Main Effects $\quad 39$

Hypothesis 2. Interaction Effects 39

Hypothesis 3. Mediation $\quad 40$

Hypothesis 4. Moderated Mediation $\quad 41$ 
CHAPTER THREE: METHODS

Participants $\quad 42$

Procedure $\quad 43$

Measures $\quad 45$

Independent Variables $\quad 45$

Demographic Information $\quad 45$

Placement History $\quad 45$

Sexual Abuse $\quad 45$

Physical Abuse $\quad 46$

Witnessing Domestic Violence $\quad 47$

Witnessing Community Violence 47

Witnessing Community Violence in the Community 48

$\begin{array}{ll}\text { Dependent Variable } & 48\end{array}$

Sexual Behavior Problem $\quad 48$

Moderating Variables $\quad 49$

Trauma Symptoms $\quad 49$

Sexual Concerns $\quad 49$

Mediating Variables $\quad 50$

Emotion Dysregulation $\quad 50$

CHAPTER FOUR: RESULTS

Description of the Final Sample $\quad 51$

Correlation Analyses $\quad 53$

Comparisons Based on Gender $\quad 55$

Main Effects $\quad 56$

Moderation (PTS) $\quad 56$

Moderation (SC) $\quad 57$

Mediation Analyses $\quad 58$

Results of the Mediation Analyses $\quad 60$

Moderated Mediation Analyses $\quad 62$

Results of the Moderated Mediation Analyses $\quad 64$

CHAPTER FIVE: DISCUSSION

Main Effects: Risk Factors $\quad 75$

$\begin{array}{ll}\text { Interactions } & 78\end{array}$

Mediating Role of Emotion Dysregulation $\quad 81$

Strengths and Limitations $\quad 83$

Limitations Related to Variables $\quad 84$

Conclusion $\quad 86$

$\begin{array}{ll}\text { REFERENCES } & 88\end{array}$

$\begin{array}{ll}\text { VITA } & 97\end{array}$ 


\section{LIST OF TABLES}

Table 1. Sample Characteristics $\quad 52$

Table 2. Severity of Sexual Behavior Problems 53

Table 3. Summary of Hierarchical Regression Analysis for Variables Predicting Sexual Behavior Problems 65

Table 4. Moderation: Sexual Abuse by PTS Symptoms 66

Table 5. Moderation: Physical Abuse by PTS Symptoms 66

Table 6. Moderation: Sexual Abuse by PTS Symptoms by Gender 67

Table 7. Moderation: Physical Abuse by PTS Symptoms by Gender 67

Table 8. Moderation: Domestic Violence (Witness) by PTS Symptoms by Gender Shift $\quad 68$

Table 9. Moderation: Domestic Violence (Victim) by PTS Symptoms by Gender $\quad 68$

Table 10. Moderation: Community Violence by PTS

Symptoms by Gender

Table 11. Moderation: Exposure to Sexual Violence by PTS Symptoms by Gender $\quad 69$

Table 12. Moderation: Sexual Abuse by Sexual Concerns (sc) 70

Table 13. Moderation: Sexual Abuse by Sexual Concerns (sc) by Gender

Table 14. Least Squares Regression Results for Moderated Mediation: Sexual Abuse

Table 15. Least Squares Regression Results for Moderated Mediation: 
Table 16. Least Squares Regression Results for Moderated Mediation: Domestic Violence (Witness)

Table17. Least Squares Regression Results for Moderated Mediation: Domestic Violence (Victim)

Table 18. Least Squares Regression Results for Moderated Mediation: Exposure to Community Violence

Table 19. Least Squares Regression Results for Moderated Mediation: Exposure to Sexual Violence 


\section{LIST OF FIGURES}

Figure 1. Hypothesized Interaction Model 2-A 35

Figure 2. Hypothesized Interaction Model 2-B 36

Figure 3. Hypothesized Interaction Model 2-C 36

Figure 4. Hypothesized Interaction Model 2-D 37

Figure 5. Hypothesized Interaction Model 2-E 37

Figure 6. Hypothesized Mediation Model 38

Figure 7. Hypothesized Moderated-Mediation Model 39

Figure 8. Mediation Model $\quad 59$

Figure 9. Mediation Model 1: Sexual Abuse 61

Figure 10. Mediation Model 2: Physical Abuse 61

Figure 11. Mediation Model 3: Domestic Violence (Witness) 61

Figure 12. Mediation Model 4: Domestic Violence (Victim) 62

Figure 13. Mediation Model 5: Community Violence 62

Figure 14. Mediation Model 6: Exposure to Sexual Violence 62 


\begin{abstract}
The purpose of the current study is to investigate the traumatic history of youths in the foster care system presenting with sexual behavior problems. Moreover, cooccurring trauma symptoms will be investigated as possibly contributing to the severity of sexual behavior problems in this population. The present study has four primary goals: (1) This study will focus on identifying traumatic experiences that are associated with sexual behavior problems in children and adolescents in the child welfare system; (2) Cooccuring levels of trauma symptoms including posttraumatic stress symptoms (PTS) and sexual concerns (SC; Briere, 1996) will be tested as possible moderators between significant traumatic risk factors and severity of sexual behavior problems demonstrated by youth; (3) Current emotional dysregulation will be tested as a possible mediator in this relationship; (4) Gender will be tested as a moderator in the mediation analyses. Hypotheses and planned data analyses will be based on theory and past research findings in the field of traumatic stress. Both will be discussed in the following sections in greater detail.
\end{abstract}




\section{CHAPTER ONE INTRODUCTION}

In response to the increased incidence of Sexual Behavior Problems (SBPs) among children and adolescents, there has been a dramatic increase in research focusing on this topic in the past twenty years (Araji, 1997). This interest in SBPs has been paralleled by an increase in the number practitioners and juvenile court resources devoted to youth with SBPs (Araji, 1997). National figures suggest that the number of youth engaging in sexual offenses, a subset of SBP, is also alarmingly high (Gray, Busconi, Houchens \& Pithers, 1997). Specifically, the data indicate that $40 \%$ of all child sexual abuse is performed by youth less than 20 years of age, and that children under the age of 13 perform $13 \%$ to $18 \%$ of all childhood sexual offenses (Social and Rehabilitation Services, 1995). These alarming figures elucidate the importance of this topic for both researchers and clinicians, and the need to identify risk factors that may play a role in the development of SBP in youths who may be at high risk.

While problematic sexual behaviors in children and adolescents have frequently been thought of as a direct result of sexual abuse, research has shown that sexual abuse should be considered a "frequent but not essential contributor" (Friedrich, Davies, Fehrer \& Wright, 2003) to the development of SBPs in both young children and adolescents. This finding suggests that other potential risk factors should also be investigated to better understand how SBPs develop. Major factors that have been found to significantly 
correlate with SBPs include experiences of maltreatment, disruption in attachment, exposure to domestic and community violence, and inappropriate sexualization (Vizard, Hickey \& McCrory, 2007; Johnson, 1998; Friedrich et al., 2003).

Considering that children in substitute care are often victims of abuse, neglect, disrupted attachment, and a host of other domestic and community stressors, it is not surprising that the rates of SBPs in this population are much higher than in the general population (e.g., Friedrich, Fisher, Dittner, Acton, Berliner, Butler, Damon, Davies, Gray \& Wright, 2001). Surprisingly, however, research exploring the correlates of SBP among youth in the child welfare system is limited relative to the proportionally higher rates of SBP in this population (Friedrich, Baker, Parker, Schneiderman, Gries \& Archer, 2005; Friedrich, 1997). Additionally, research has primarily focused on main effects and has yet to regularly study possible moderators and mediators of SBPs.

Youth entering the child welfare system often face multiple adversities above and beyond their prior abuse and neglect, and these adversities can become magnified for youth who experience sexual behavior problems. For example, due to safety concerns and the stigma associated with sexual behavior problems, these children are often at a higher risk for placement failure (Friedrich et al., 2005); further, these particular placement failures are frequently due to foster family rejection of the child, which only exacerbates the youths' tenuous attachment capacities (Friedrich et al., 2005). Youths in substitute care who present with sexual behavior problems often present with comorbid post traumatic symptoms related to their maltreatment histories. It might be that the risks associated with being in foster care and concomitant trauma symptoms 
correlate with SBPs among youth in the child welfare system, a hypothesis that has not been adequately explored in the research literature (Baker, Schneiderman \& Parker, 2001; Friedrich et al., 2005).

The purpose of the current study is to investigate the traumatic history of youths in the foster care system presenting with sexual behavior problems. Moreover, cooccurring trauma symptoms will be investigated as possibly contributing to the severity of sexual behavior problems in this population. The present study has four primary goals: (1) This study will focus on identifying traumatic experiences that are associated with sexual behavior problems in children and adolescents in the child welfare system; (2) Cooccuring levels of trauma symptoms including posttraumatic stress symptoms (PTS) and sexual concerns (SC; Briere, 1996) will be tested as possible moderators between significant traumatic risk factors and severity of sexual behavior problems demonstrated by youth; (3) Current emotional dysregulation will be tested as a possible mediator in this relationship; (4) Gender will be tested as a moderator in the mediation analyses. Hypotheses and planned data analyses will be based on theory and past research findings in the field of traumatic stress. Both will be discussed in the following sections in greater detail. 


\section{CHAPTER TWO}

\section{REVIEW OF RELATED LITERATURE}

Definition of Sexual Behavior Problems (SBP) in Youths

In 2006, the Association for the Treatment of Sexual Abusers Task Force published its report on sexual behavior problems in children. The taskforce defined sexual behavior problems in children as: "sexual behavior that is developmentally inappropriate (e.g., age inappropriate), potentially harmful to the self or others; and behavior that infringes on the rights of others" (Chaffin, Berliner, Block, Johnson, Friedrich \& Louis, 2008; TarrenSweeney, 2008; Silovsky, Niec, Bard \& Hecht, 2007). Sexually inappropriate or problematic behaviors in children and adolescents involve an array of acts, including “excessive flirtatiousness and promiscuity, self-exposure, as well as sexual acts committed against other's will” (Adam, McClellan, Douglass, McCurry \& Storck, 1995). While the term "sexual" is used in the definition of SBP in children, "the intentions and motivation for these behaviors may, or may not be related to sexual gratification or sexual stimulation" (Chaffin et al., 2006). Silovsky and Bonner (2003) argued that the behaviors may be related to natural curiosity, anxiety, imitation, attention-seeking, or self-calming. Sexual behavior problems may involve self-focused behaviors or behaviors that involve other children or adults. When behaviors involve others, there may be a difference in power, size, understanding, and consent (Chaffin et al., 2006). Since these behaviors may involve coercion and developmental inequality, they are considered to be 
more concerning problematic behaviors since they may have greater potential for harm (Chaffin et al., 2006).

The existing literature on SBPs has primarily emphasized sexual offending behavior (Caputo et al., 1998). Sexual offending committed by adolescents involves sexual behavior perpetrated against a person's will, without consent, or in an aggressive, exploitative, manipulative or threatening manner (Ryan \& Lane, 1997). Youths who sexually offend may also utilize power, force, and control to manipulate victims (both younger and same aged) to participate sexually (Ryan \& Lane, 1997). Adolescent sexual offenders have generally been classified into two groups, those who sexually offend against peers or adults and those who sexually assault children younger than themselves (Ryan \& Lane, 1997; Chaffin et al., 2006). And while children who present with sexual behavior problems have been identified as being a heterogeneous group, adolescent sexual offenders primarily tend to be male (Sylovsky \& Niec, 2002; Ryan, 1991).

The types of sexual offenses committed by youths have been found to range both in severity and intrusiveness (Snyder, 2000). Fehrenbach, Smith, Monastersky, and Deischer (1986) investigated 305 adolescents accused of committing sexual offenses were able to categorize these behaviors into 1 of 5 categories according to severity and intrusiveness of the behavior: (1) no physical contact, (2) genital fondling only, (3) oralgenital contact, (4) intercourse, and (5) some form of penetration. This categorization of sexually problematic and intrusive behaviors has been supported by other research studies investigating sexual behavior problems across age groups (Johnson, 1998). 
Incidence and Prevalence of Sexual Behavior Problems in Youths Although problematic sexual behaviors and sexual offending in children and adolescents are generally rare and are considered to be extremes of natural behaviors, there is a general agreement in the literature that there has been an increase over the last 20 years in the number of children and adolescents who demonstrate problematic sexual behaviors and are referred for child protective services, treatment, and juvenile services (Chaffin et al., 2006; Friedrich, 2001; Gray, Pithers, Busconi \& Houchens, 1999). For example, in Vermont alone between 1984 and 1994 the number of cases of sexual abuse committed by children less than 14 years old increased by $300 \%$ (Social and Rehabilitation Services, 1995). In spite of the commonly held assumption that preadolescent children may not be capable of sexual offending, the research indicates that sexual offending is not solely committed by adolescents.

The U.S. Department of Justice (Snyder, 2000) estimated that juveniles account for up to one-fifth of all rapes and almost one-half of all cases of child molestation committed each year; the median age of the offender ranges between 14 and 15 (Ryan, 1991). Based on the most current report focusing on the sexual assault of young children, using data from 12 state law enforcement agencies (1991 through 1996), youth were involved in $23.2 \%$ of all sexual assaults in the United States. Across four categories, forcible rape, forcible sodomy, sexual assault with an object, and forcible fondling, the report found that $17 \%$ of juveniles committed forcible rape, $23 \%$ were involved in a sexual assault with an object, $27 \%$ forcible fondling and $36 \%$ forcible sodomy (Snyder, 2000). Focusing on juveniles under 12 years of age, the report noted that while only a 
very small proportion of children are involved in forcible rapes $(1 \%)$, the remainder of sexual assaults (16\%) were distributed equally across the age categories (Snyder, 2000).

Any figures on the prevalence of sexual behavior problems and sexual offending committed by youths should be examined with care due to issues related to use of appropriate measurement, terminology, and underreporting. For example, Johnson (1999) noted that the term "children with sexual behavior problems" is used differently across the research community. While some studies use this term to refer to children who are engaging in serious sexual behaviors, other studies may use it to refer less intrusive and atypical behaviors. This discrepancy in nomenclature across studies trying to capture incidence rates may create unreliable figures.. Researchers have also argued that sexually intrusive behaviors and offenses committed by children may go unreported given the secrecy surrounding sexual abuse (Tarrens-Sweeney, 2008). Nonetheless, national figures indicate that a significant proportion of sex crimes committed in the United States are indeed committed by juveniles under the age of 18 (Snyder \& Sickmund, 1999).

Typical Sexual Behaviors across Ages

The issue of which behaviors are considered developmentally normal or appropriate for a child at various ages is always at the center of any framing of SBPs (Johnson, 1998). Problematic sexual behaviors in children have been long assumed to be "deviations from the normal course of sexual development" (Araji, 1997). According to this perspective, children and adolescents, much like adults, are considered to be sexual beings (Rutter, 1971). Therefore, before one can label children's sexual behaviors as 
problematic or indicative of a problem, it is necessary to better understand which behaviors are typically present and appropriate at various ages.

Friedrich (1998) found that children under the age of 5 who have not been sexually abused were more likely to exhibit sexual behaviors than older children, attributing this fact to natural curiosity. Children's behaviors varied in frequency, with the most frequent behaviors including self-stimulation, exhibitionism and behaviors related to personal boundaries (Friedrich, 1998). Similarly, in a survey of 564 daycare providers, Phipps-Yonas, Yonas, Turner, and Kauper (1993) found that sexual behavior was common in both boys and girls between the ages of one and six. Children (30\%) were reported to occasionally masturbate, or use dolls to act out sexual activity. Providers also noted that older children (ages 4-6) were more "sexually curious about the mechanics of sexual activity" as well as more likely to engage in sexual games. Other behaviors, including French kissing, pretend intercourse, inserting objects into vagina or buttocks, or asking children to kiss their genitalia have been observed with very low probabilities (Friedrich, 1998).

After age 5 Friedrich (1998) found that sexual behavior in children tends to drop off until the age of 11 for girls, and age 12 for boys. Regardless of ethnicity or socioeconomic status, girls and boys presented with similar sexual behaviors. Researchers have argued that this drop off could be due to the fact that children start to adopt social norms regarding sexuality and sexual behaviors, and demonstrate a growing capacity to modulate behavior (Sandnabba, Santilla,\& Wannaes 2003). Adolescence is considered to be a time of both physical and cognitive development (Feldman \& 
Middleman, 2002). Accordingly, it is expected that youths in this age group may engage in sexual behaviors at higher rates than younger children. While adolescents may engage in sexual behaviors both coital and non-coital, including intercourse, masturbation, mutual masturbation, and oral sex, sexual activity that involves the use of force or coercion infringes on the rights of others, and as such is a threat to others and warrants unique empirical attention (Feldman \& Middlemann, 2002).

As the research discussed above appears to suggest, it is typical for children to engage in occasional sexualized behaviors including self-stimulation, exploration of self and others' bodies, or exhibition of genitalia (Friedrich, 1991). While these behaviors are more developmentally appropriate for younger children, with age these behaviors seem to become less common across situations as youth incorporate social norms regarding which behaviors are appropriate and acceptable.

If sexual behavior is considered normal to some extent across different ages, where do parents, treatment providers, and professionals draw the line between normal and problematic? When do normal sexual behaviors become atypical, inappropriate or even dangerous? By and large, researchers have argued that sexual behaviors in youths fall along a continuum from age-appropriate exploration to highly aggressive sexual behaviors (Bonner et al., 1999). Johnson (1993) developed a continuum of sexual behaviors that encompasses the range of behaviors both typical and abusive. Johnson included four groups along this continuum. The first group, which has been shown to be the largest, includes children with "natural and healthy sexual behaviors". The remaining three groups include children with problematic behaviors. The groups are: "sexually 
reactive," "children engaged in extensive mutual sexual behaviors," and "children who molest." Johnson (1993) use the broad categorization "children with sexual behavior problems" to describe all children who engage in increasingly disturbed sexual behaviors, that was deemed intrusive, excessive, developmentally atypical, and unsafe.

\section{Sexual Behavior Problems: Gender Differences}

As has been previously discussed, females generally constitute only a small proportion of youths who demonstrate sexually aggressive and problematic behaviors. Snyder (2000) found that overall, $6 \%$ of the offenders who sexually assaulted juveniles were female. Friedrich's investigation of sexual behavior problems in children in a national sample indicates that males and females demonstrate the same types of sexual behaviors up to age 12 (Friedrich et al. 1997; Gray et al. 1997) with no significant gender differences found on the Child Sexual Behavior Inventory (CSBI; Friedrich, 2001) up to age 12 (Gray et al., 1997). However, after age 12, boys begin to demonstrate significantly higher scores on the CSBI (Gray et al., 1997).

Research on juvenile female sexual offenders is still relatively scarce in comparison to male sexual offenders (Mathews, Hunter \& Vuz, 1997). Despite the few studies available focusing primarily on female juvenile sexual offenders, findings suggest that there may be differences in the etiology and presentation of sexually problematic behaviors between females and their male counterparts. Much like males, histories of female juvenile sexual offenders are marked by distress, abuse, maltreatment, family instability and violence (Mathews et al., 1997). A history of physical and sexual abuse has been identified as a strong link to sexual offending by females (Araji, 1997; Gray et 
al., 1997). Interestingly, the literature has found that compared to males, female sexual offenders present with higher rates of co-occuring internalizing disorders such as depression, anxiety and posttraumatic stress symptoms (Vick, Mcroy \& Matthews, 2002). Also, Finally, compared to males, females have been found to begin perpetrating at a younger age (6 versus 8 years) (Vick, Mcroy \& Matthews, 2002).

Therefore, like males, female sexual offenders have histories of traumatic experiences and stress: however the literature indicates that female sexual offenders have a "higher threshold for the externalization of experienced developmental trauma" compared to males (Mathews et al., 1997 p. 194). Females have been shown to "generally be less likely than males to manifest the effects of maltreatment in the form of interpersonal aggression or violence" (Mathews et al. 1997, p. 194). When females do present with sexual behavior problems or sexually offend, it is more likely that they have experienced extremely high levels of developmental trauma and stress. While no theory or definite rationale has been established for this difference, Mathews and his colleagues (1997) argue that both biological and socialization factors may play a role.

Therefore, the literature indicates that girls experience fewer SBPs in response to the same traumatic experiences, suggesting that gender should moderate the relationship between risk and SBPs. The current study hypothesizes that gender will moderate the relationship between risk and severity of SBPs, such that girls with SBPs will present with more severe maltreatment histories compared to males presenting with similar level of offending. 
Risk Factors Associated with Sexual Behavior Problems in Youths Many factors influence the course of sexual development, including social context, individual characteristics, disruptive experiences, and any interaction of these (Araji, 1997). Understanding how the factors come together to bring forward sexual behavior problems in children and adolescents is still developing. Nonetheless, the literature indicates that traumatic experiences may play a significant role in the development and maintenance of sexually problematic behaviors (Tarren-Sweeney, 2008).

Researchers and mental health professionals have argued that childhood sexual abuse predisposes children to engage in frequent and intrusive sexual behaviors (KendallTackett et al., 1993). While the notion that childhood sexual abuse plays a significant role in the etiology of many youth's sexual behavior problems may be intuitive and commonsense, research also suggests that childhood sexual abuse may not be the only traumatic factor that influences the development and severity of SBPs (Tarren-Sweeney, 2008). As the forthcoming discussion will highlight, various traumatic experiences may impact the severity of sexual behavior problems in youths. Moreover, the literature discussed will reveal that not only direct victimization but also witnessing violence and traumatic events may relate to sexually problematic behaviors in children and adolescents (Tarren-Sweeney, 2008).

For example, non-sexual maltreatment and exposure to domestic violence have also been associated with higher rates of SBPs (Friedrich, Davies, Fehrer \& Wright, 2003). Friedrich and his colleagues (2003) found that exposure to domestic violence was 
a stronger predictor of sexual behavior problems in children than sexual abuse (Friedrich et al., 2003). This provocative finding is part of a recent generation of research that has served to broaden the number of variables used in the SBP literature (Sylovsky, \& Letourneau, 2008).

The recent expanded focus has also generated theorizing on the diverse developmental mechanisms that may play a role in the etiology of these problematic behaviors in children (Tarren-Sweeney, 2008). The following sections explore various risk factors that have been shown to strongly correlate with sexual behavior problems in children. These include sexual abuse, physical abuse, family dysfunction, and exposure to violence. While the literature has primarily focused on the impact of exposure to domestic violence, the current study will investigate exposure to community violence and how it may relate to the sexual behavior problems in youths. In discussing these risk factors, the following review will also discuss how researchers have begun to theorize about the mechanism (s) involved in bringing forward these behaviors.

\section{Childhood Sexual Abuse}

It is common consensus that childhood sexual abuse (CSA) is a traumatic occurrence (World Health Organization, 2002) and a major risk factor for a variety of immediate and long-term problems (Briere, 1994; Kendall-Tackett et al., 1993). A strong link has been established between CSA and sexual behavior problems in children, adolescents, and adults. Experiencing childhood sexual abuse has been shown to be associated with higher rates of aggression, anxiety, depression, externalizing problems, internalizing problems, sexualized behavior problems, and withdrawal. In her landmark 
review of 45 studies comparing sexually abused children to non-abused children, Kendall-Tackett et al. (1993) found a clear difference in symptomatology between groups. Moreover, in summarizing her findings, Kendall-Tackett and her colleagues (1993) found that sexual abuse accounted for $43 \%$ of the variance in sexualized behaviors in children and that the presentation of sexual behavior problems was one of only two outcome variables that significantly differentiated sexually abused from non-sexually abused children.

Among adolescents, empirical research has found a similar correlation between childhood sexual abuse and sexual offending. Studies have repeatedly found that sexually offending adolescents were more likely to have experienced sexual victimization as children compared to non-abusing youths (Burton, Lynn Miller \& Tai Shill, 2002). In a High-School sample, Lodico, Gruber, \& DiClemente (1996) highlighted this relationship by finding that students who were sexually abused as children reported engaging in coercive sexual activity compared to the adolescents who reported no sexual abuse history.

These initial findings clearly outline the harmful influence sexual abuse may have on youths' sexual behavior and sexual development (Kendall-Tackett, 1993). A notable limitation regarding Kendall-Tackett's review is that the majority of studies possessed small sample sizes and used a variety of definitions for sexual behavior problems. As studies focusing primarily on sexual behavior problems became more prevalent and began to investigate sexually problematic behaviors in larger samples, the data have begun to reveal that childhood sexual abuse may not be the sole variable impacting 
Physical Abuse

A history of physical abuse has been shown to be associated with the presence of sexual behavior problems in children (Friedrich, et al., 2003; Gray et al, 1999; Letourneau et al. 2004; Silovsky \& Niec, 2002). Silovsky and Niec (1999) investigated the history of thirty-seven pre-school children with sexual behavior problems and found that a large portion of the sample (47\%) had experienced physical abuse or witnessed domestic violence. Similar findings were observed by Gray and his colleagues (1999), who studied 127 children between the ages of 6 and 12 years with sexual behavior problems. In their sample, $84 \%$ had a sexual abuse history, $48 \%$ had a physical abuse history, $33 \%$ had an emotional abuse history, and $18 \%$ had a history of neglect. While these studies suggest a clear relationship between physical abuse and the development of sexual behavior problems and sexual offending, many studies fail to take possible confounding variables into consideration (e.g., co-occurring sexual abuse).

Merrick, Litrownik, Everson, and Cox (2008) specifically studied 690 children without reported sexual abuse histories. They found that reports of physical abuse were associated with more sexualized behaviors. Further, they identified physical abuse as being predictive of intrusive sexual behaviors in boys and boundary problems in girls (Merrick et al., 2008). Merrick and her colleagues' findings replicate those by Friedrich et al. (2003) and Becker (1998), who found that physical abuse was more related to coercive and aggressive sexual behaviors in adolescent males. The reported findings suggest that besides sexual abuse, other forms of maltreatment during childhood may be linked to the development of problematic sexual behaviors in children and adolescents. 


\section{Family Characteristics}

The literature indicates that various family characteristics commonly discussed under the broad category of "family dysfunction" (Tarren-Sweeney, 2008) may also predispose youth to sexual behavior problems. The factors that have been studied and found to strongly correlate with sexual behavior problems include poor attachment and parent-child relationship and exposure to domestic violence (Tarren-Sweeney, 2008).

\section{Exposure to Domestic Violence}

"Families of children with sexual behavior problems are marked by an array of characteristics indicative of parental and familial distress" (Gray, Busconi, Houches \& Pithers, 1997). The literature on juvenile offending has long supported the relationship between exposure to domestic violence and juvenile offending (Caputo, Frick, \& Brodsky, 1999) including the role of exposure to domestic violence in adolescent and child sexual offending (Tarren-Sweeney, 2008). Findings from various studies have consequently shown a link between exposure to domestic violence between parents and sexually aggressive behaviors in youths (Gray et al., 1997; Friedrich et al., 2003).

In investigating family characteristics of 726 to 12 -year-old children who had engaged in sexual misbehavior, Gray and colleagues (1997) found that witnessing violence between parents was the most powerful characteristic to predict sexual behavior problems in children. Their findings were replicated by Friedrich et al. (2003) who found that in a sample of 2-12 year old children $(\mathrm{N}=2311)$, family factors potentiated the development of sexual behavior problems in children who were sexually abused. After family income and controlling for the effect of experiencing sexual abuse, they observed 
that exposure to family violence was a significant predictor of sexual behavior problems in young children. Similar findings were reported by Schwartz, Cavanaugh, Pimental, and Prentky (2006) when reviewing the records of 813 sexually abusive children and adolescents. They found that across age, sexually abusive children were more likely to have witnessed domestic violence as well as sexual deviance within the home.

Specifically focusing on an adolescent sample, Caputo, Frick, and Brodsky (1999) established that the witnessing of severe domestic violence was related to juvenile sex offending. Moreover, the results of their study indicated that witnessing inter-parental violence was related to more intrusive contact offending.

Lewis, Shanok, and Pincus (1981) tested the link between family violence and sexual offending, reporting that the majority of juvenile sexual offenders in their study (79\%) had directly observed violence within the family. Comparably, only $20 \%$ of their non-violent offending comparison group had observed violence within the family. Interestingly, Smith (1988) reported that the severity of offenses committed by adolescent sexual offenders was directly related to the amount of violence that was perpetuated toward the offenders' mother.

While there is an apparent link between exposure to domestic violence and sexual behavior problems in youths, prior research has done less to tease apart the potential confounding relationship between physical abuse and witnessing domestic violence on the development of sexually aggressive behaviors. No research has examined the distinct impact of both on the development of sexual behavior problems, but studies investigating aggressive behaviors in youth provide the literature with interesting findings that may 
generalize to the study of SBPs. Looking at the combined impact of physical abuse and exposure to domestic violence on rates of externalizing problem behaviors, Hughes, Parkinson, and Vargo (1989) found that both variables had a unique impact on externalizing behaviors. These early findings suggest that experiencing multiple traumatic events or risk factors may be related to more severe sexual behavior problems and offending in youths. It also supports the current study's plan to investigate a population with complicated histories of maltreatment and exposure to violence.

\section{Witnessing Community Violence}

A review of the literature indicates that exposure to community violence has not been investigated as a direct predictor or contributor to the development of sexual behavior problems or sexual aggression in children and adolescents. While it has long been assumed and accepted that direct victimization is traumatic and has a psychological impact, researchers have argued that witnessing community violence, especially if repeated, may also have a cumulative psychological impact (Bell, \& Jenkins, 1991; Rosenthal, 2000).

Exposure to community violence has been found to be associated with increased levels of aggression and trauma symptoms in youths, both symptoms that have been associated with the presence of sexual offending and sexual behavior problems in youths (Chaffin et al., 2006). Longitudinal studies also indicate that experiencing community violence is related with increases in children's antisocial behavior and aggression (Gorman-Smith, Tolan, 1998; Farrell \& Bruce, 1997). Rosenthal (2000) found that exposure to recurring community violence is related to a wide range of psychological 
trauma symptoms including anxiety, depression, and dissociation in late adolescence.

Witnessing community violence has not been directly linked to the development of sexual aggression and sexual behavior problems. However there is a clear lack of research looking directly at this relationship. Moreover, studies looking at the effects of exposure to community violence have generally focused primarily on witnessing of nonsexual violence. The current study plans to focus on both the effects of witnessing community violence as well as piercing out the possible association between witnessing violent sexual acts in the community and the presence of sexual behavior problems. Finally, as exposure to community violence may occur with other types of violence, the current study will examine the differential impact of various forms of violence including, physical, sexual, intra-familiar, and community. In using a child welfare population, which has been exposed to multiple forms of violence and adversity, the current study will have the opportunity to better understand how they may impact the development on sexual behavior problems in youths.

\section{Theoretical Conceptualization}

Researchers have made great strides in identifying the multitude of correlates and risk factors related to sexual behavior problems; however, the actual mechanism or mechanisms accounting for these correlates are still somewhat speculative (TarrenSweeney, 2008). A number of theories have been proposed to explain the relationship between traumatic experiences and the presence of sexually inappropriate behavior in adults (Becker, 1998) including physiological, social learning, behavioral, and developmental theories (Ryan \& Lane, 1997). However, to date there is no single 
generally accepted theory regarding the development of sexual behavior problems in youths.

The literature discussed up to this point indicates that both directly experiencing trauma (e.g. physical abuse, sexual abuse) as well as witnessing violence (e.g. domestic violence, community violence) may play a significant role in the development of sexual behavior problems in youths. The fact that a variety of stressors seem to be related to the development of sexually problematic behaviors suggests that multiple conceptual models (Kendall-Tackett, 1993) may explain the relationship between trauma and behavior problems. There is evidence to suggest that both a trauma focused and social learning model may best explain the relationship between traumatic events and subsequent behavior problems and sexual offending (Tarren-Sweeney, 2008).

Traumagenic Model

To explain the relationship between directly experiencing traumatic events such as sexual abuse and the consequent development of sexual behavior problems Finkelhor and Browne (1985) argued for a trauma mechanism. Finkelhor's traumagenic model (1985) proposed that "the experience of sexual abuse can be analyzed in terms of four trauma causing factors." The four factors (traumagenic dynamics) are traumatic sexualization, betrayal, powerlessness and stigmatization. He argued that these dynamics "alter children's cognitive and emotional orientation to the world, and create trauma by distorting children's self concept, world view and affective capacities" (Finkelhor et al., 1985; Johnson, 1998).

Finkelhor and Browne found that traumatic sexualization best predicted future 
sexual behavior problems and sexual offending in youths (1985). Finkelhor defined traumatic sexualization as the "process in which a child's awareness and knowledge of sexual issues is impacted" at different stages of their development causing children to become confused about what behavior are normal and typical. He argued that traumatic sexualization "includes a variety of processes such as the inappropriate conditioning of the child's sexual responsiveness and the socialization of the child into faulty beliefs and assumptions" about sexual behavior (Finkelhor et al., 1985; Kendall-Tackett, 1993). For example, through their sexual abuse experiences, children may develop distorted views of sexual norms, become sexual aggressive, or tend to extremes, with either a heightened sensitivity and attraction to sexual behavior or highly negative feelings to all sexual activity (Finkelhor et al., 1985).

This model effectively describes the possible development of sexually inappropriate behaviors in sexually abused children, but it also sheds light on similar processes that may explain the impact of physical abuse on later sexual offending and sexual behavior problems. While physical abuse may lack the sexual component found in sexual traumatization, much like sexual abuse it does involve a threat to a child's safety, and the possibility of traumatization. Moreover, it also impacts children's understanding of which behaviors are appropriate with respect to relating to others.

While not explicitly discussed by Finkelhor (1985), the powerlessness component of the traumagenic model may help explain the relationship in the literature between physical abuse and the development of sexually aggressive behaviors. Finkelhor and 
Browne (1985) argued that the continued invasion committed by others gives rise to feelings of vulnerability, and may damage self-efficacy in children. Particularly, the "repeated frustration of not being able to stop or escape from the noxious experience" may cause children to try to gain control of conflicting emotions by recapitulating the experience by trying to abuse others (Kendall-Tackett, 1993). It is possible that the powerlessness associated with being physically abused leads some youth to seek mastery over their experience through aggressiveness, including sexual aggressiveness, which deflects powerlessness to the victim.

Following from the traumagenic model, the current study will investigate whether trauma symptoms are associated with the occurrence of SBPs in youths. It is hypothesized that children who respond to traumatic experiences (e.g., physical abuse, sexual abuse, and exposure to violence) with post-traumatic stress symptoms will present with more severe SBPs. These hypotheses will be tested using moderation.

The development of sexual behavior problems and sexual behaviors that may infringe on the rights of others may also involve a learning mechanism (Burton, 2000; Cicchetti, Toth, \& Maughan, 2000; Rossman, 1999). Research has supported a social learning hypothesis for the development of sexual offending by adolescents and children (Burton, 2000). Bandura and Waiters (1963) stated that "deviant sexual responses appear to be sometimes the result of parental encouragement and reinforcement of inappropriate sexual behaviors". When sexual behaviors that are aggressive and inappropriate for the child's age are paired with positive reinforcement, the child may learn to regard these 
child's age are paired with positive reinforcement, the child may learn to regard these behaviors as appropriate, normal, and worthwhile. Bandura argued that the perceived rewards may be physiological, social, or psychological (Bandura, 1986; Ryan, 1989).

Pither's findings (1998) supported the application of a social learning perspective, noting that parents of youth with SBP engage in conduct that "either modeled or reinforced children's inappropriate behaviors." Studying a sample of 127 6-12 year old children who engaged in developmentally unexpected sexual behaviors, Pithers and colleagues (1998) found that many of the children lived in a household in which inappropriate behaviors were modeled by parents and caregivers. In about half of the sample, children had witnessed parents engaged in domestic abuse or other forms of violence. Although these behaviors may not be sexual in nature, they are considered much like sexual behavior problems to be inappropriate and atypical.

Beyond behaviors within the home, researchers have argued that exposure to community to violence and sexually violent acts in the community may also reinforce or model aggressive behaviors (Buka, Stichick, Birdthistle \& Earls, 2001). While the relationship between community violence and externalizing problems in children and adolescents has been investigated extensively (Buka et al., 2001), research has not examined how witnessing community violence may relate to the presence of sexual behavior problems in youths. The current study hypothesizes that exposure to community and domestic violence may act to provide youths with a model that reinforces problematic sexual behaviors. 
Moderating Variables: Posttraumatic Stress Symptoms (PTS) and Sexual Concerns (SC) The child and adolescent psychopathology literature has called for more research examining potential moderators involving the relationship between stressors, risk factors and psychological problems (Grant, Compas, Thurm, McMahon, Gipson, Campbell, Krochock, \& Westerholm, 2006). Moderation is said to be occurring when the strength of the relationship between two variables is dependent on a third variable. (Preacher, Rucker \& Hayes, 2007). The identification of variables that accentuate or reduce the relationship between risk factors and sexual behavior problems in youths could have critical implications for therapeutic intervention.

Previous studies have primarily focused on static demographic factors that may play a role in increasing the likelihood of developing behavior problems; the most commonly tested moderators by far have been age and gender. To date, no study has explored the possible moderating association between co-occurring trauma symptoms (Posttraumatic stress symptoms, Sexual Concerns) and severity of sexual behavior problems. As noted by Grant et al. (2006), research frequently fails to investigate fluid variables, such as trauma symptom severity, as possible moderators in the relationship between traumatic experiences and outcome variables.

Prior research with the current sample data has investigated trauma symptoms as a mediator between risk variables (e.g., sexual abuse, witnessing domestic violence) and sexual offending. Edlynn (2007) hypothesized that a history of sexual abuse would predict trauma symptoms (e.g. depression, anxiety), and aggression, and that these symptoms would be associated with SBPs. Traumatic experiences, particularly 
witnessing community violence, was found to be related to traumatic symptoms. However, the results did not support Edlynn's (2007) mediational hypotheses.

The current study is unique in exploring the potential moderating role of trauma symptoms and sexual concerns (Briere, 1996) on SBPs. This approach is justified for two reasons. First, research has provided a link between trauma symptoms in children and adolescents and sexual behavior problems (Pithers et al., 2002). Second, many youth who experience risks, such as sexual and physical abuse, do not necessarily develop trauma symptoms. Several commonly studied protective factors have been shown to decrease the likelihood of trauma symptoms among highly vulnerable youth in the child welfare system (e.g., Leon, Ragsdale, Miller, \& Spaccirelli, 2008). Therefore, it is possible that risk factors are more associated with SBPs when trauma symptoms and increased sexual anxiety are prominent, indicating moderation. Moreover, the impact of different trauma symptoms may differ for females compared to males. Based on the above review, it may be hypothesized that internalizing symptoms will moderate the impact of trauma for girls while externalizing symptoms may play a more prominent role for males.

Trauma Symptoms in Children with Sexual Behavior Problems

The literature discussed up to this point suggests that there is a high incidence of trauma exposure among youths who present with sexual behavior problems. Most of these traumatic experiences have been found to be associated with sexual behavior problems in youth. The severity and number of trauma exposures experienced by youth who sexually offend or present with SBPs, "combined with their psychological and 
developmental vulnerabilities and their lack of protective factors" place them at high risk for developing post-traumatic symptoms (McMackin, 1998). Indeed, figures indicate that a substantial number of youth with sexual behavior problems also present with PTS and related internalizing symptoms (Pithers, \& Gray, 1998; Sylovsky \& Niec, 2002). Studies examining posttraumatic symptoms in children and adolescents with sexual behavior problems found that rates of symptoms ranged between 17\% and 54\% (Pithers, \& Gray, 1998; Sylovsky \& Niec, 2002).

Along with posttraumatic stress symptoms, researchers have also identified sexual concerns (SC) as an internalizing symptom in youths who present with sexual behavior problems (Briere, 1996). As a construct, sexual concerns include symptoms of both sexual preoccupation and distress (Briere, 1996). Briere (1996) indicated that sexual preoccupation involves increased precocious sexual thoughts and fantasies (Briere, 1996; Noll, Horowitz, Bonanno, Trickett, \& Putnam, 2003) while sexual distress refers to anxiety relating to unwanted sexual feelings and fears about being sexually exploited (Briere, 1996). Youths' who experience sexual distress often present as fearful of others, untrusting, anxious, and easily upset by sexual thoughts (Briere, 1996; Briere \& Elliot, 1994). Overall, the negative affect, disturbing thoughts, mistrust, and impaired social relations associated with sexual concerns represent a distressing symptom picture, and can have an ongoing negative impact on youths' development (Briere, 1996).

The trauma literature has found that in response to traumatic events (both direct victimization and witnessing) males and females differ with respect to presentation of internalizing and externalizing problems (Fitzpatrick \& Boldizar, 1993). In response to 
exposure to violence research findings indicate that being victimized as well as witnessing violence is more significantly related to PTS symptoms in females than males. At the same time boys and girls differ not only in the intensity of PTS, but also in the types of behavioral outcomes that occur later. Whereas girls tend to react to trauma with more internalizing behaviors, boys are at increased risk for developing externalizing problems (Jenkins \& Bell, 1994; Gorman-Smith \& Tolan, 1998).

\section{Trauma and Emotion Dysregulation}

At the core of traumatic stress in response to negative events, is the youth's inability to properly regulate internal states, emotions and impulses (van der Kolk, 2005). Researchers and theorists have suggested that maladaptive emotional development or emotional dysregulation plays an important role in the development of psychopathology (Shields \& Cicchetti, 1998).

Emotional dysregulation refers to an emotional response that is poorly modulated and does not fall within the conventionally accepted range of emotional responses. Emotional dysregulation has been associated with early psychological trauma, and chronic maltreatment (van der Kolk, 2005). As will be discussed, emotional dysregulation has also been linked to behavioral problems that interfere with youths relationships with peers as well as caregivers. While researchers have looked at the role of emotion dysregulation in the association between victimization and aggression, information is still lacking on the potential impact of this construct on the development of problematic sexual behaviors.

Emotion regulation is considered to be a broad construct (Cole, Martin \& Dennis, 
2004) that can be best understood as "all the extrinsic and intrinsic processes responsible for monitoring, evaluating and modifying emotional reactions, especially their intensive and temporal features, to accomplish one's goals" (Thompson, 1994, p. 27-28). The ability to appropriately integrate, modulate and respond to demands and stressors in one's environment is one that has been identified as being disrupted and negatively impacted by exposure to trauma and various forms of maltreatment (van der Kolk, 2005; Shields and Cicchetti, 1998). For example Shields and Cicchetti's (1998) investigation of 141 children with a history of maltreatment indicated that a history of abuse predicted emotion dysregulation in the form of socially inappropriate emotion expression. Other studies have shown that physical abuse puts children at a higher risk for disruptive behaviors and aggression (Kaufman \& Cicchetti, 1989). Shields and Cicchetti (1998) also noted that independent observers rated children who had a history of maltreatment as more verbally and physically assaultive and socially inappropriate. Across age groups research has consistently found that children with maltreatment histories "evidence atypical emotional development" (Shields and Cicchetti, 1998). Pre-school and schoolage children identified as maltreated tend to be more angry, reactive, and irritable than their non-maltreated peers (Alessandri, 1991).

Youth who have experienced extensive histories of trauma and maltreatment (e.g. physical abuse, sexual abuse, and domestic violence) have been identified as being especially prone to demonstrate reactive aggression in response to potentially threatening situations. (Cummings, Hennessy, Rabideau, \& Cicchetti, 1994). Moreover, children with intense and chronic maltreatment histories have also been shown to "be more vigilant to 
aggressive stimuli and to attribute hostile intent in ambiguous social situations, suggesting that they may experience an exaggerated need to defend themselves from perceived social stress and threats" (Shields \& Cicchetti, 1998). In light of these findings, researchers have also argued that children who grow up in environments that are unstable, inconsistent and threatening may not have the opportunity to learn and develop adaptive behavioral responses to situations that they may perceive as threatening or provoking, especially if violence is modeled as an acceptable way of managing conflict and stress.

Children's mastery of emotion regulatory processes "emerge within the context of the caregiver-child relationship" (van der Kolk, 2005). Children learn early on to regulate their own emotions and behaviors through consistent interactions with caregivers. This interaction allows children to develop "internal working models" or an internalization of the affective and cognitive characteristics of their primary caregivers (Bowlby. 1982). The development of healthy emotion regulation relies and is intrinsically intertwined with children's patterns of attachment. Secure parent-child attachments have been shown to better modulate emotional responses and appropriately respond to stressors in their lives as well as come up with appropriate strategies to appropriately respond to their surroundings (van der Kolk, 2005).

Because the development of "[emotion] regulatory processes emerge within the context of the caregiver-child relationship, disruptions in the development of affect regulation are likely in youths who have experienced maltreatment" (Cicchetti \& Toth, 1995, p. 547). Howes and Cicchetti (1993) argued that "in accord with a developmental 
psychopathology perspective, adequate affect regulation would serve as a foundation for the development of effective relations with peers, while affect-regulatory failures would place a child at risk for future difficulties" (Howes \& Cicchetti, 1999). The experience of multiple traumatic events and maltreatment is therefore considered to be a disruptive force in the lives of youths' and related to emotional dysregulation. The stressors discussed up to this point are generally extremely overwhelming for both young children and adolescents. Since youth's currently in substitute care have experienced a history of care that was inconsistent, intrusive, neglectful and often violent, it could be expected that this sample will present with significant difficulties with emotional regulation.

Children who experience trauma both at home and in the community, and especially children who are removed from their home and placed in substitute care, are raised in an environment that often lacks constancy and predictability. A sense of predictability interferes with children's development of object constancy. In other words, children lack a representation of their inner world or their surroundings, which in turn causes them to lack a good sense of cause and effect of their own contributions to what happens to them and their impact on others. This lack of a consistent "inner road map" that children may reference or use to guide their actions and behaviors, causes them to act more impulsively rather than appropriately plan their actions (van der Kolk, 2005).

Of particular interest to research on the development of sexual behavior problems and sexual offending is the notion that emotion dysregulation and impulse control may play a role in the development of psychopathology, including sexual behavior problems. An inability to modulate or control ones emotions and behaviors properly has been 
observed in adult sexual offenders, and only recently researchers have begun to investigate children and adolescents (Howells \& Day, 2004). Research on the effects of exposure to domestic and community violence has long supported the impact on children's emotion regulation and the relation to aggressive and negative interpersonal behaviors. Schwartz and Proctor (2000) evaluated the hypothesis that violent victimization is associated with aggressive behavior through mediation by emotion dysregulation. Investigating 285 children between fourth and sixth grade Schwartz and Proctor (2000) found that emotion dysregulation mediated the relationship between victimization and aggression. Schwartz and Proctor noted that children who were exposed to direct victimization were characterized by impaired regulation of negative affect which mediated the relation between victimization and aggression. Emotion dysregulation was not found to mediate the relation between witnessing community violence and aggression (Schwartz \& Proctor, 2000).

To date, no research has investigated the possible moderating role of gender in the impact of emotion dysregulation in the development of sexual behavior problems. It is unclear whether emotion dysregulation mediates the relationship between traumatic experiences and behavior problems differently for males compared to females (Schwartz \& Proctor, 2000). Accordingly, the current study plans to explore the possible moderating role of gender in this relationship. 


\section{Current Study}

\section{Children with Sexual Behavior Problems in Substitute Care}

Investigating sexual behavior problems in children in the welfare system provides a unique opportunity to test a model that incorporates various traumatic risk factors beyond just sexual and physical abuse. Tarren-Sweeney (2008) argued that researchers might learn more about the mechanisms that account for sexual behavior problems in children if we investigate samples with what he defined as "complex exposure to maltreatment and adversity" (p. 185). Children who enter substitute care are a unique population that offers researchers the opportunity to do just this. Often children in substitute care have extensive maltreatment histories, and experience disturbances in living situations, inconsistent caregiving and attachment difficulties (Tarren-Sweeney, 2008; Friedrich, Baker, Parker, Schneiderman, Gries, \& Archer, 2005). Research on the nature and etiology of sexual behavior problems in children in substitute care is of even greater importance because of the unique implications these problematic behaviors might have on children's treatment placement opportunities. In addition to the risks youth are exposed to before entering the child welfare system, research suggests that these youth often experience further risks simply by entering the foster care system (Benedict, Zuravin, Somerfield, \& Brandt, 1996) and that these risks can have additional deleterious effects. For example, youth in the child welfare system often experience unstable and multiple placements. Newton, Litrownik, \& Landsverk, 2000). Millham, Bullock, Hosie, and Haak (1986) reported that $56 \%$ of children had three or more placements after only two years in substitute care; the effect of this disruption can have both immediate and 
long-term negative outcomes including internalizing and externalizing behaviors, difficulty trusting adults, and difficulty forming attachments with adults and children (Newton et al., 2000).

Research on Children with Sexual Behavior Problems in Substitute Care

To date, few studies have specifically investigated sexual behavior problems in children in substitute care, in spite of the clear implication these behavior problems may have for the safety and security of children involved (Friedrich et al., 2005). Beyond just issues of safety, further research on sexual behavior problems in children in substitute care is necessary as it can provide researchers and practitioners with more information on possible mechanisms that play a role to bring these problematic behaviors forward.

The current study attempts to add to the limited amount of information available on children in substitute care who present with sexually problematic behaviors. The current study seeks to also gain an improved understanding of the specific factors related the child's environment and past experiences that may be associated with the development of sexually problematic behaviors including sexual offending. The current study's sample of youths present with extensive traumatic histories and a significant proportion presents with traumatic symptoms. Therefore, a model that focuses on traumatic experiences will be tested to determine if trauma symptoms including posttraumatic stress symptoms and sexual concerns plays a moderating role in the relationship between traumatic risk factors and SPBs. Possible gender differences will also be explored to better understand whether different variables will moderate the relationship differently for males opposed to females. Exploratory analyses will be 
conducted to test the role of emotion dysregulation in the presentation of sexual behavior problems.

\section{Study Hypotheses}

\section{Main Effects}

Each risk factor will uniquely predict severity of sexual behavior problems when controlling for the influence of the other risk factors. No gender differences are expected.

a. Sexual abuse will be significantly related to severity of youths' sexual behavior problems.

b. Physical abuse will be significantly related to severity of youths' sexual behavior problems.

c. Level of exposure to domestic violence will be significantly related to severity of youths' sexual behavior problems.

d. Level of exposure to community violence will be significantly related to severity of youths' sexual behavior problems.

e. Level of exposure to sexual acts in the community will be significantly related to severity of youths' sexual behavior problems.

\section{Interaction Effects}

Trauma symptoms (TSC-C; Briere, 1997) will moderate the relationship between negative and potentially traumatic experiences (e.g. sexual abuse, physical abuse, witnessing domestic violence, witnessing community violence) and the severity of sexual behavior problems. The purpose of this study is to investigate the specific paths by which PTS may influence the relationship between specific risk factors and Sexual 
behavior problems. Severity of PTS is expected to influence the relationship between traumatic risk factors and severity of SBP. In this model, PTS is depicted as a moderator. PTS may thereby influence the strength or direction of the Trauma - Sexual behavior problems relationship. It is hypothesized that PTS will significantly moderate the relationship between Trauma and SBPs for females but not for males. Clinically significant levels of PTS symptoms are expected to increase the severity of sexual behavior problems.

a. Trauma symptoms will moderate the relationship between sexual abuse and the severity of sexual behavior problems in youths as reported by therapists.

Figure 1: Hypothesized Interaction Model 2-A:

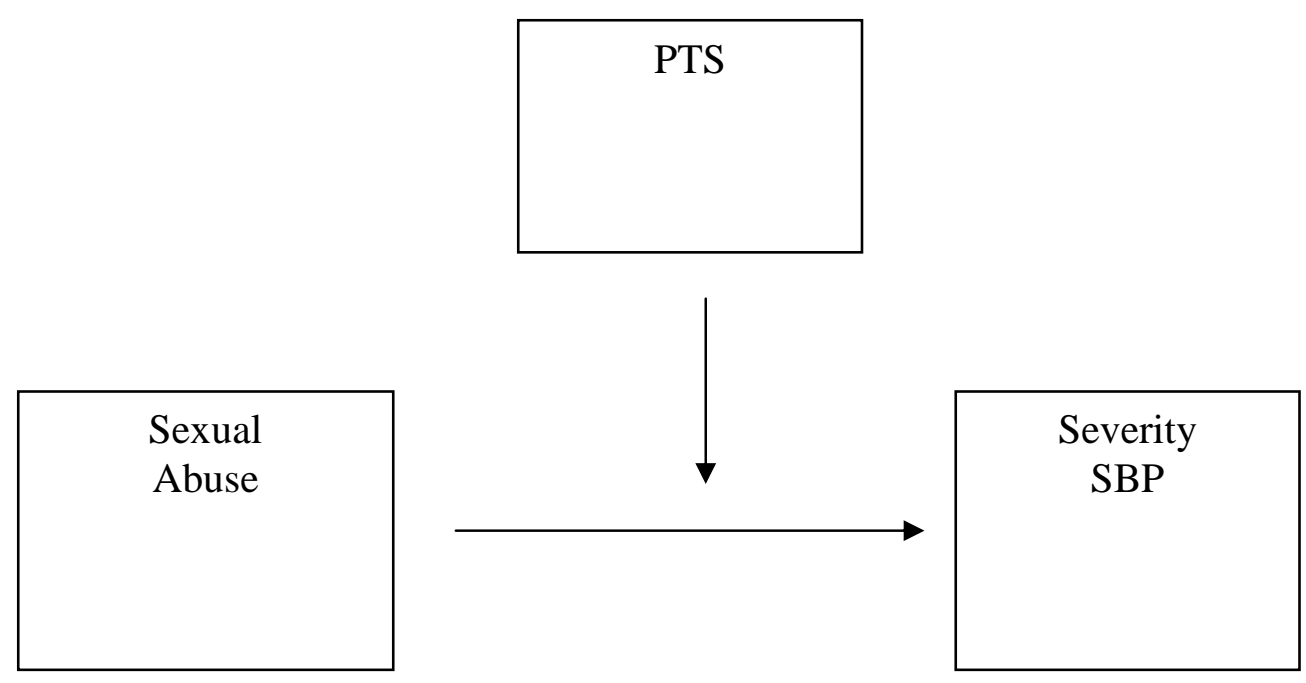


b. Trauma symptoms will moderate the relationship between physical abuse and the severity of sexual behavior problems in youths as reported by therapists.

Figure 2: Hypothesized Interaction Model 2-B:

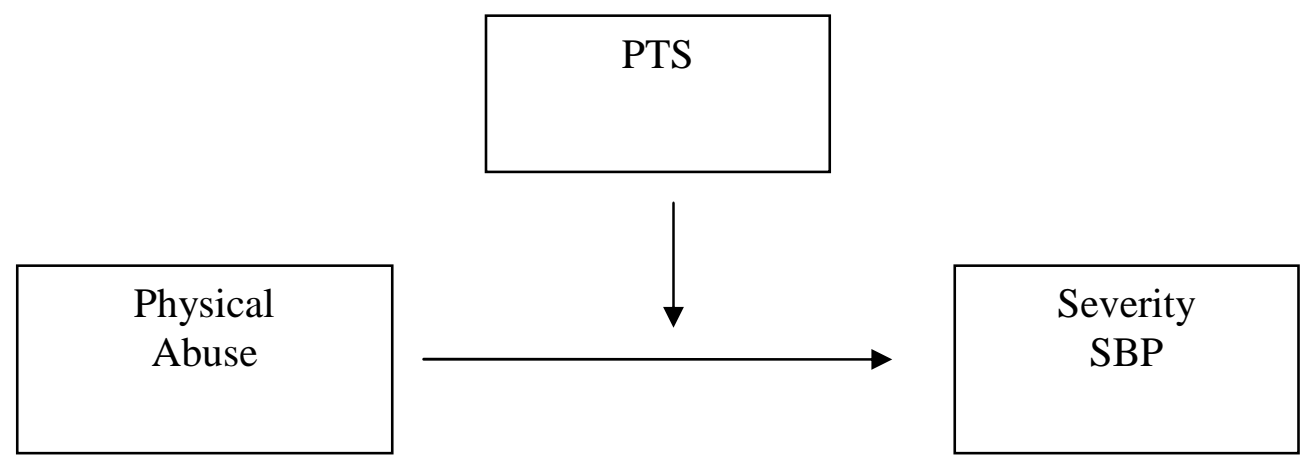

c. Trauma symptoms will moderate the relationship between Witnessing Domestic

Violence and the severity of sexual behavior problems in youths as reported by therapists.

Figure 3: Hypothesized Interaction Model 2-C

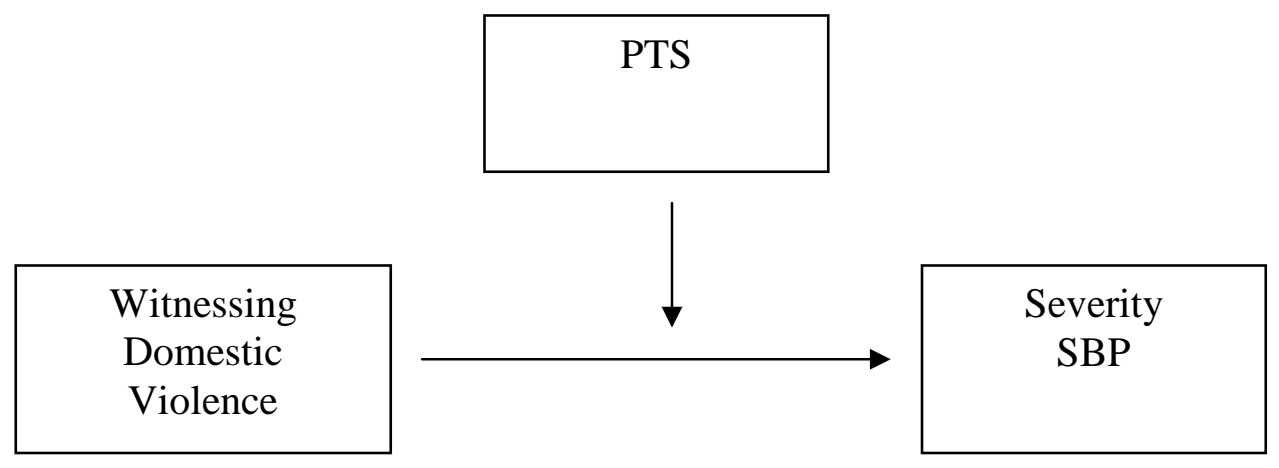


d. Trauma symptoms will moderate the relationship between Witnessing Community Violence and the severity of sexual behavior problems in youths as reported by therapists.

Figure 4: Hypothesized Interaction Model 2-D

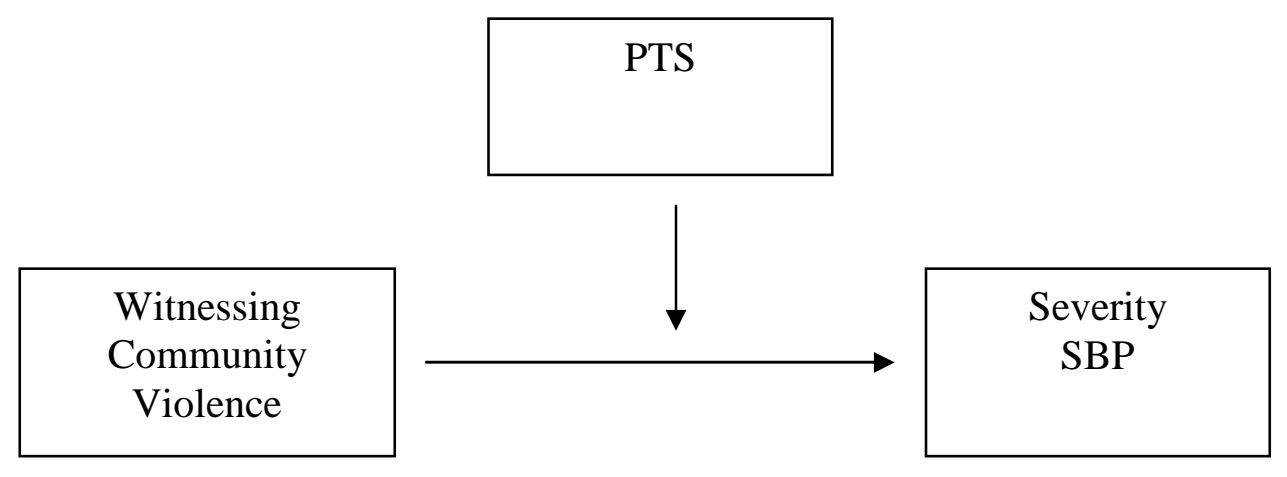

e. Trauma symptoms will moderate the relationship between Witnessing Sexual Violence in the Community and the severity of sexual behavior problems in youths as reported by therapists.

Figure 5: Hypothesized Interaction Model 2-E

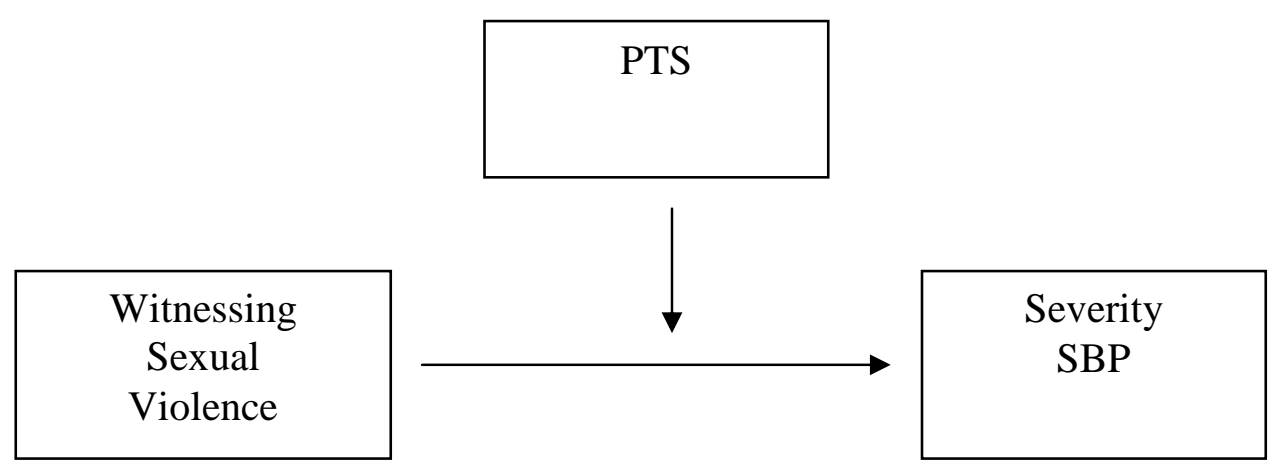


Gender Differences

Analyses will be run to determine whether there are gender differences with respect to the moderating impact of PTS symptoms.

\section{Mediation}

It is hypothesized that children maltreatment histories will present with higher emotional dysregulation as reported by their treatment providers.

Figure 6: Hypothesized Mediation Model

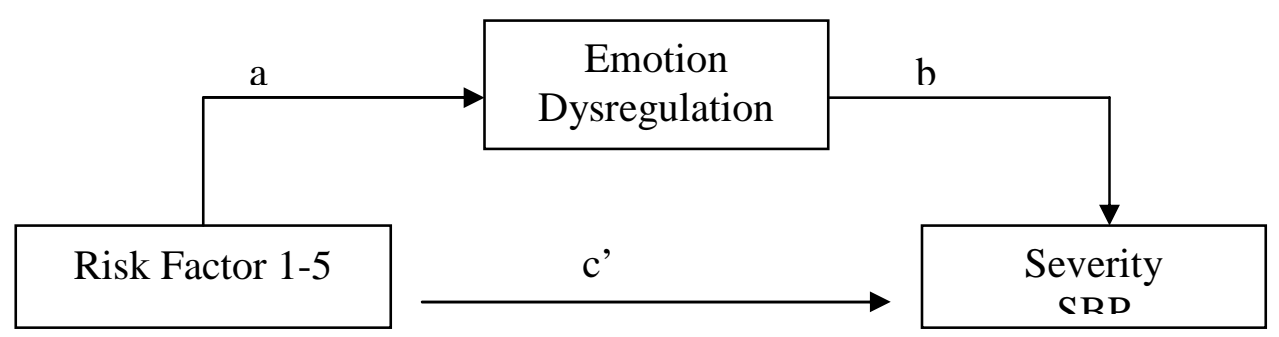

\section{Moderated-Mediation}

To analyze possible gender differences in mediation models (Emotion Dysregulation), an exploratory moderated mediation analysis will be conducted to test for significant mediations. It is hypothesized that gender will moderate the mediating role of emotion dysregulation. Specifically it is hypothesized that it will moderate the relationship between the mediator (Emotion Dysregulation) and the outcome variable as depicted below: 
Figure 7: Hypothesized Moderated Mediation Model

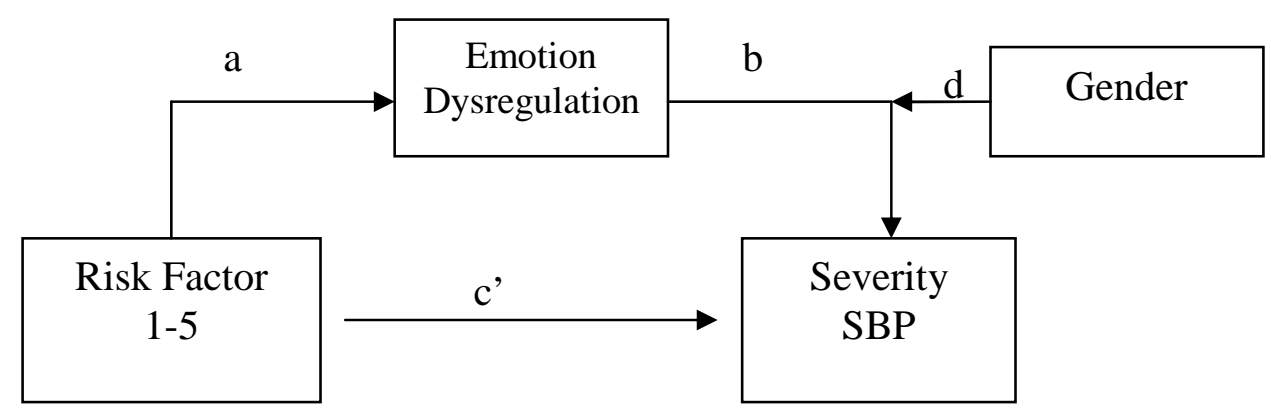

Hypothesis 1. Main Effects

Planned Analyses

a. Preliminary correlation analyses will be run using SPSS 16, to determine significant associations among variables.

b. Ordinary Least Square regressions will be run using SPSS 16 to analyze relationship between risk factors and severity of sexual behavior problems. All predictors will be entered in the first block simultaneously using a stepwise method, after controlling for age and gender. The severity of sexual behavior problems will be entered as the dependent variable in this analysis.

c. A separate analysis will be run with the file split according to gender to determine possible differences based on participants' gender.

\section{Hypothesis 2. Interaction Effects}

To test these hypotheses Ordinary Least Square regressions will be run using SPSS 16. Age and gender (both at Time 1) will be entered as controls in the first block 
along with the predictor variable (Time 1). In the second block we will enter the interaction term created by centering the predictor variable and multiplying it with the moderator (PTS). Severity of Sexual behavior problems (Time 1) will be entered as the dependent variable.

Separate analyses will be run for each predictor: Sexual Abuse, Physical Abuse, Exposure to Domestic Violence, Exposure to Community Violence, and Exposure to Sexually Violent Acts. (5 separate analyses).

To test whether PTS will moderate the impact of predictor variables differently based on gender, we will split the file based on gender and the same analyses will be run again. This time only age will be entered as a control in the first block.

To test whether SC as a possible moderator, Ordinary Least Square regressions will be run using SPSS 16. Age and gender (both at Time 1) will be entered as controls in the first block along with the predictor variable (Time 1). In the second block we will enter the interaction term created by centering the predictor variable (Sexual Abuse) and multiplying it with the moderator (SC). Severity of Sexual behavior problems (Time 1) will be entered as the dependent variable.

To test whether SC will moderate the impact of sexual abuse differently based on gender, we will split the file based on gender, and the same analyses will be run again. This time only age will be entered as a control in the first block.

\section{Hypothesis 3. Mediation}

A series of regression analyses will be conducted in order to examine whether emotion dysregulation mediates the link between traumatic risk factors and severity of 
sexual behavior problems. Following Baron and Kenny (1986), there are four steps in establishing mediation: Step 1, involves showing that the independent variable is correlated with the criterion variable; Step 2, involves showing that the independent variable is correlated with the mediator; Step 3, involves establishing that the mediator affects the criterion variable when controlling for the independent variable; and lastly Step 4, involves showing that the mediator variable mediates the relationship between the independent and criterion variable (the relationship becomes non-significant when mediator is entered into the model). It should be noted that according to most analysts Step 1 is not required if steps 2 and 3 are met (Preacher \& Hayes, 2007).

\section{Hypothesis 4. Moderated Mediation}

Moderated mediation happens if the mediating process that is responsible for producing the effect of trauma exposure on the severity of sexual behavior problems depends on the value of a moderator variable, in this case gender. In other words, if gender is a moderator, then it would mean that the mediating process that intervenes between trauma exposure and the outcome is different for girls and boys. What varies as a function of the moderator is not the magnitude of the overall treatment effect on the outcome but the mediating process that produces it.

The plan is to follow directions discussed and laid out in Muller, Judd, and Yzerbyt (2005). . Step by step calculations will be discussed in the Results section. 


\section{CHAPTER THREE}

\section{METHOD}

\section{Participants}

Data for the current study were taken from the "Children With Sexual Behavioral Problems Longitudinal Study" (Spaccarelli, 2002), originally conducted by the Child Abuse Unit for Studies, Education and Services (CAUSES) research agency. The available dataset included extensive data on wards of the Department of Child and Family Services (DCFS) in Cook County, IL who presented with sexual behavior problems as observed and reported by their caregivers (i.e., foster parents, residential staff). The primary goal of the original 2002 study was to provide DCFS with a detailed description of the array of issues and problems of youth being screened for sexual behavior problems. Researchers collaborated with DCFS to both recruit and collect data from eligible youth.

The sample for the current study consists of 163 participants (120 male and 43 female) ranging in age from 10 and 18 years $(M=13.64, S D=2.16)$. Ethnic representation was predominantly African American (80\%), with small proportions of Caucasian (13\%), Latino (5\%), and multi-racial (2\%) youth. These proportions roughly match the ethnic proportions for wards in substitute care in the area, indicating equal likelihood of group membership (i.e., identification as sexually aggressive youth) for all 
ethnic groups.

Of the youth in the sample, $41 \%$ were in foster placement, $9 \%$ were living with relatives, and 50\% were in settings such as residential facilities, group homes, or shelters at the time of screening for the study. Youth had experienced between 2 and 23 placements prior to the screening incident; the mean number of placements was 7.8 ( $S D=$ 4.1). $42 \%$ of the total sample were found to have suffered (per DCFS file review or self report) sexual victimization. 53\% were victims of physical abuse (also per DCFS records or self-report).

\section{Procedure}

In Chicago, DCFS policy requires that Unusual Incident Reports (UIRs) be filed by the youth's caseworker for events such as elopement, abuse, or in the case of youth in this study, the occurrence of sexual behavior problems. Once these youth were identified, consent to participate was obtained. Acquiring consent included first verifying state guardianship and obtaining consent from the DCFS guardian, and after a discussion with the youth's caseworker regarding the appropriateness of participation, informed consent was obtained from the foster caregiver and assent from the participating youth. Both youth and caregiver received compensation for their participation ( $\$ 35$ gift card for each participation episode). Youth and their guardians participated in data collection at their place of residence. Each data collection lasted several hours. Data were collected from youth, their caregivers, and from DCFS electronic paper records. While supervised by trained research assistants, youth were administered a series of surveys on a laptop computer (between 375 and 540 items). As youth worked on the laptops, their caregivers 
completed a survey via pencil and paper (one of two versions of the 247-item Caregiver Survey, either for youth ages 12 and under, or youth ages 13-17).

Since not all youth involved in this study resided in a foster home different accommodations were necessary depending on current living situation. For youth living in residential facilities (i.e. inpatient settings, group homes, hospital), residential staff completed a Residential Staff Survey, either for youth ages 12 and under, or youth ages 13 to 17.

Youth and caregiver data in this study were collected between 3 and12 months from the time of the screening incident. This time range was due to variability in responsiveness of caseworker and the guardianship office to the consent process, as well as difficulties in scheduling and coordinating data collection with foster parents and various responsible agencies. The enrollment period lasted from May 2000 until the end of February 2003.

Along with interviews, data collection also involved a review of comprehensive DCFS family files for each participant and a separate incident-screening file. Research assistants reviewed each document in the comprehensive family file and coded information pertaining to family composition and history, abuse/neglect history, placement and educational history, and sexual behavior incidents. Information was also retrieved from the electronic integrated database of the DCFS Office of the Research Director. Data were collected on subjects' demographics, legal status changes (e.g. temporary custody, state guardianship, etc.), placement history, and abuse/neglect allegations. Finally, data were also collected from providers of therapeutic services. 
Therapists were interviewed by trained research assistants. Information was gathered regarding type of treatment provided, compliance, severity of the problem behavior(s), family involvement and therapist impressions regarding youth characteristics and progress.

To review, data was obtained through (1) Caregiver Questionnaire, (2) Screening file review, (3) DCFS family file review, (4) DCFS Electronic Records review, (5) Therapy Provider Interview (6) Subject Interview (12 years and older).

Measures

Independent Variables

Demographic Information

Source: DCFS records. Basic demographic information on each participating youth (e.g. race, gender, and age) was obtained from file reviews and coded by trained research assistants.

\section{Placement History}

Source: DCFS records. Children's DCFS electronic records were reviewed for the number of substitute care placements, and type of placements currently resided in (i.e. foster care, residential treatment, kinship care, or group home).

Sexual Abuse

Source: DCFS records. Sexual victimization was assessed by self-report of a variety of sexual experiences in the home. The self-report measure consisted of 57 items and was constructed specifically for the larger study (Spaccarelli et al., 2001). The measure was designed to allow youth to report victimization based on their memories of 
discrete events. Once the nature of the event was established via initial questions, the measure then assesses the details of the event with follow-up probes (e.g., "Did that person kiss or touch your mouth or body?"). Youth were coded as having been sexually abused if they endorsed any of the following three yes-no items: 1) "Have you felt like someone made you do sexual stuff when you really didn't want to?", 2) "Other than who we just talked about, did another person make you do sexual things when you didn't want to?", and 3) "Other than those who you may have just talked about, have you ever done sexual stuff with someone much older than you (5 years or more)?". DCFS electronic records were also examined for history of investigations in which the youths were named as victims of indicated reports of sexual abuse Sexual abuse was coded as having occurred if there was a confirmed report of sexual abuse noted in the child's DCFS chart. Also, sexual abuse was also coded as having occurred if the child made a definite report but formal evaluations by authority were at the time inconclusive (McClellan, McCurry, Ronnei, Adams, Storck, Eisner, \& Smith, 1997).

Physical Abuse

Source: DCFS File; Youth Self-Report. Children were asked eight questions adapted from the Conflicts Tactics Scale (Straus, Hamby, Boney-McCoy, \& Sugarman, 1996) about whether or not they had ever experienced physical, non-sexual abuse. They responded on a 1 to 5 scale indicating frequency, with scores of one indicating not at all and scores of five indicating frequent physical abuse. A single score representing the mean of the items was computed, and the mean on this measure was $1.7(S D=0.9)$. Internal consistency for this scale was .90 . 
Witnessing Domestic Violence

Source: Youth Report. Nine items adapted from the Conflict Tactics Scale (Straus, Hamby, Boney-McCoy, \& Sugarman, 1996) assessed the youth's exposure to violence between adults in the home. Previous studies using this measure indicate good reliability and validity with adult and adolescent samples, with internal consistency ranging from .79-.95 (Parrott \&Zeichner, 2003; Stets, 1991). Youths indicated on a scale of 1 (never) to 5 (more than 10 times) how often they had witnessed an act of violence both at home. Items asked about witnessing physical conflict between adults in the home.(e.g. "One of the adults pushed, grabbed or showed another adult."). A single score representing the mean of the items will be computed. Internal consistency for this scale was .94. The mean score for witnessing domestic violence was $1.72(S D=1.02)$

\section{Witnessing Community Violence}

Source: Youth Report. 12 items, adapted from the Survey of Children exposure to Violence (Richters, \& Saltzman, 1990), identified youths' exposure to violence in their community. Good validity and reliability has been reported for this measure in other studies looking at exposure to community violence (Howard, Cross, Li, \& Huang, 1999). Youth rated on a five-point frequency scale how often they have witnessed violent events in their neighborhoods: $1=$ never, $2=$ Only once, $3=2-5$ times total, $4=6-10$ times total, and 5= More than 10 times. Example items included "seen someone use an illegal weapon" and seen someone stab or try to stab someone." A single score representing the mean of the items will be computed for the scale. Internal consistency for this scale was .89. The mean score for witnessing community violence was $1.89(S D=0.87)$ 
Witnessing Sexual Violence in the Community

Source: Youth Report. Four items, adapted from the Survey of Children exposure to Violence (Richters, \& Saltzman, 1990), identified youths' exposure to sexually violent behaviors in their community. Youth rated on a five-point frequency scale how often they have witnessed violent events in their neighborhoods: $1=$ never, $2=$ Only once, $3=2-5$ times total, 4=6-10 times total, and 5= More than 10 times. Items included "seen others having sex with whores or prostitutes", "seen someone flash or expose his her private parts to other people", "seen someone trying to make another person have sex or trying to rape someone", "seen a group of people trying to get someone to have sex". A single score representing the mean of the items will be computed for the scale. Internal consistency for the scale was .80. The mean score for witnessing sexual violence in the community was $1.58(S D=.88)$

\section{Dependent Variable}

\section{Sexual Behavior Problem}

Source: Treatment Provider. The investigators (Spaccarelli, Edejer, Bushell, Karaitis, \& Jones, 2001) coded severity of sexual behavior problems on an 6-point scale. Treatment providers were asked to describe the most severe of past sexual inappropriate behavior demonstrated by the youth. Response options included $1=$ no clear sexual offenses (i.e. sexualized behavior only); 2 = non-contact offense(s) (i.e. public masturbation, flashing); 3 = contact offense(s) involving no penetration, no physical force; 4 = contact offense(s) involving no penetration but physical force; $5=$ contact offenses(s) involving penetration, no physical force; and $6=$ contact offense(s) involving 
offense(s) both penetration and physical force.

Moderating Variables

Trauma Symptoms

Source: Youth Report. The Posttraumatic Symptoms Scale (PTS) of the Trauma Symptom Checklist for Children (Briere \& Runtz, 1989) included 10 items. Previous research has established this measure to have good reliability and validity, including utility for measuring symptoms related to childhood maltreatment (Briere et al,, 2001). Youths rated each item on a four-point interval scale, in reference to symptoms they have experienced in the past six months: $1=$ Never, $2=$ Sometime, $3=$ Lots of times, $4=$ Almost all the time. Example items include " bad dreams or nightmares," and "Can't stop thinking about something bad that happened to me." Cronbach's Alpha for the current measure was .83. Raw Scores were converted into T scores. Participants who had a T score of 60 (Briere, 1996) and above were categorized as being in the clinically significant range for experiencing trauma symptoms and were coded " 1 "; scores under 65 were coded " 0 ".

Sexual Concerns

Source: Youth Report: Sexual Concerns (SC) subscale of the Trauma Symptom Checklist for Children (TSCC; Briere, 1996). The sexual concerns scale measures sexual distress and preoccupation. Items tap sexual thoughts or feelings that are atypical when occurring earlier than expected in development or with greater than usual frequency (e.g., “Thinking about having sex" and "Having sex feelings in my body"). Items also tap unwanted sexual responses or conflicts (e.g., "Thinking about sex when I don't want to"), 
negative responses to sexual stimuli (e.g., "Getting upset when people talk about sex"), or fear of being sexually exploited (e.g., "Not trusting people because they might want sex"). Ten items were scored on a 4-point scale, with $0=$ Never, $1=$ Sometimes, $2=$ Lots of times, and $3=$ Almost all of the time. Cronbach's Alpha was .83. Raw Scores were converted into T scores. Participants who had a T score of 65 and above were categorized as being in the clinically significant range and coded "1"; scores under 65 (Briere, 1996) were coded " 0 ".

Mediating Variables

Emotion Dysregulation

Source: Treatment Provider. For the purpose of the current study treatment providers were asked to respond to eight questions addressing youth's ability to regulate their emotions in response to stressful situations. Sample items include "He/She is able to appropriately express negative feelings" and "He/She gets out of control when angry or upset". Items were rated on a four point scale with $1=$ Very Much, $2=$ Somewhat, $3=\mathrm{A}$ little, and $4=$ Not at all. Cronbach's alpha was .83. A single score representing the mean of the items will be computed for the scale. The mean score for Emotion Dysregulation was $16.33(S D=4.60)$. 


\section{CHAPTER FOUR}

\section{RESULTS}

\section{Description of the Final Sample}

General descriptive statistics for the current sample are provided in Tables 1 through 5. Tables 1 and 2 present sample characteristics. The mean age of the 163 participants was $13.64(S D=2.16)$. There were 120 males $(74 \%)$ and 43 females $(26 \%)$ in the final sample. The mean severity of sexual behavior problems (Table 2) in the sample was $4.49(S D=2.51)$, which puts the average youth between a "4" (Non-Genital fondling) and a "5" (Genital fondling). This suggests that the sample presents with significant sexual behavior problems. With respect to risk factors, $41 \%$ of the sample was sexually abused, and 53\% was physically abused (Table 1). On average the sample experienced moderate levels of trauma symptoms; $22 \%$ of the sample had clinically significant sexual concerns, and $18.4 \%$ had clinically significant posttraumatic stress symptoms (Briere, 1996). The mean level of emotional dysreglation for the current sample was $16.33(S D=4.59)$ indicating youth have difficulty. Appropriately expressing negative feelings and maintaining control when angry or upset. (Table 3). The mean for witnessing domestic violence was $1.75(S D=1.03)$ and the mean for witnessing community violence was $2.10(S D=0.91)$. Finally, a total of $84(53 \%)$ participants reported previously witnessing any sexual crimes in the community. 
Table 1

Sample Characteristics Characteristic

$\mathrm{N}$

$\%$

Sexual Abuse

None

82

50.3

Non-Penetration

26

18.3

Penetration

34

20.9

Physical Abuse

None

Less Serious

More Serious

PTS Symptoms

Non-Clinical

Clinical

Missing

Sexual Concerns

Non-Clinical

Clinical
36

31

62.6

18.4

$\begin{array}{ll}31 & 19.0\end{array}$

$\begin{array}{ll}96 & 58.9\end{array}$

22.1

19.0 
Table 2

Severity of Sexual Behavior Problems

Severity of SBP N (163) \%

None

25

15.3

Sexualized Behavior Only

2

1.2

Non-Contact

13

8.0

Non-Genital fondling

27

16.6

Genital Fondling (No

33

20.2

Penetration)

Genital Fondling (Attempted

6

Penetration)

Oral Penetration

18

11.0

Vaginal/Anal Penetration

Missing

4

2.5

\section{Correlation Analyses}

Correlation analyses (Table 3a-3c) revealed a significant and positive association between age and severity of sexual abuse $(.23, p<.01)$, indicating that older youths experienced more severe levels of sexual abuse. Age was significantly and negatively associated with severity of sexual behavior problems $(-.21, p<.01)$, indicating that older youths tended to present with less severe sexual behavior problems. Age was also significantly and positively associated with levels of emotion dysregulation $(.25, p<.01)$, with older youth demonstrating more problems with effective emotion regulation. A weak positive but significant correlation between gender and severity of sexual behavior 
problems $(.16, p<.05)$ revealed a tendency for males to present with more severe sexual behavior problems. Gender was significantly and negatively associated with sexual concerns $(-.22, p<.01)$; females presented more frequently with clinically significant sexual concerns.

Surprisingly, none of the risk factors (i.e. Sexual abuse, Physical abuse, Domestic Violence (Witness, Victim), Community Violence, Community Sexual Violence) were significantly associated with severity of sexual behavior problems. The same trend was observed when the sample was broken down by gender (Tables 3a-3c).

As predicted, correlation analyses revealed significant and positive associations among risk factor and trauma symptoms. This pattern indicates that children in the current sample were exposed to different forms of trauma and maltreatment. Sexual abuse was significantly associated with witnessing domestic violence $(.21, p<.05)$, being a victim of domestic violence $(.27, p<.01)$ and exposure to sexual violence in the community $(.34, p<.01)$. Sexual abuse was also significantly and positively associated with symptoms of post-traumatic stress $(.26, p<.01)$ and sexual concerns $(.41, p<.01)$. Interestingly, sexual victimization, along with all other risk factors (physical abuse, witnessing domestic violence, being a victim of domestic violence, and exposure to community and sexual violence) was not significantly associated with emotion dysregulation.

Physical abuse was found to be positively and significantly associated with witnessing $(.36, p<.01)$ and experiencing domestic violence $(.61, p<.01)$, and exposure to community violence $(.25, p<. .01)$. Experiencing physical victimization was significantly 
and positively associated with experiencing significant symptoms of post-traumatic stress $(.25, p<.01)$ and sexual concerns $(.20, p<.05)$.

Witnessing domestic violence was found to be positively and significantly associated with exposure to community violence $\left(.61 p^{<.01)}\right.$ and symptoms of posttraumatic stress $(.31, p<. .05)$. While witnessing domestic violence was not significantly associated with traumatic sexual concerns, direct victimization was positively and significantly correlated with traumatic sexual concerns $(.29, p<.01)$.

Exposure to community violence as well as witnessing specific sexually violent acts in the community was found to significantly and positively correlate with both posttraumatic stress symptoms $(.36, p<.01 ; .44, p<.01)$ and sexual concerns respectively $(.29, p<.01 ; .19, p<.05)$.

\section{Comparisons Based on Gender}

Males and females were compared on the dependent variable using independentsamples t-tests. On average, males presented with significantly more severe sexual behavior problems $(M=4.73, S D=2.54)$ compared to females $(M=3.79, S D=2.31)$ $t(157)=-2.07, p<.05$. With respect to risk factors, analyses revealed no significant difference between genders. One way Analysis of Variance (ANOVA) revealed a significant difference at a .05 significance level with respect to traumatic sexual concerns based on gender $F(1,130)=, p<.01$. Females were more likely than males to present with sexual concerns. No differences between boys and girls were found with respect to emotion dysregulation or PTS symptoms. 


\section{Main Effects}

Individual risk factors (severity of sexual abuse, severity of physical abuse, witnessing and experiencing domestic violence, exposure to community and sexual violence) were entered into an Ordinary Least Squares regression model to examine the relationship between risk factors and severity of sexual behavior problems when controlling for the effects of the other risk factors. Age and gender were entered using a forward entry procedure into the first block. All risk factors were entered into the second block. All variables were centered prior to conducting the analysis. When controlling for age and gender, none of the risk factors were significantly related to severity of sexual behavior problems (Table 4).

\section{Moderation (PTS)}

To test whether any relationship between risk factors and sexual behavior problems was moderated by Post Traumatic Stress Symptoms (PTS), ordinary least squares regressions were run using a hierarchical procedure. Age and gender were entered into the first block using the forward entry procedure. Risk factors (e.g., physical or sexual abuse, witnessing domestic or community violence), and the moderator (PTS symptoms) were entered into the second block, and the interaction term (risk factor by PTS moderator) was entered into the third block. Separate regressions were run for each risk factor for a total of six regression analyses Analyses revealed no significant effects involving any of the risk factor by PTS symptoms interactions predicting severity of sexual behavior problems at the .05 significance level. To test whether any relationship between risk factors and sexual behavior problems was moderated by PTS symptoms 
based on gender, ordinary least square regressions were also run to determine gender differences. For these analyses age was entered as a control into the first block using forward entry procedure. Gender, PTS symptoms, and risk factor were entered into the second block. Finally the two interaction terms (Risk factor by PTS, and Risk Factor by PTS by Gender) were entered into the third block. Separate regressions were run for each risk factor for a total of six regression analyses

Analyses revealed no significant three way interaction effects at the .05 significance level. Tables 5a through $5 f$ present results for analyses testing PTS as a possible moderator. Tables $6 \mathrm{a}-6 \mathrm{f}$ present results for analyses testing for gender differences.

\section{Moderation (SC)}

To test whether any relationship between risk factors and sexual behavior problems was moderated by Sexual Concerns (SC), ordinary least squares regressions were run using a hierarchical procedure. Age and gender were entered into the first block using forward entry procedure. Severity of sexual abuse, and moderator (Sexual Concerns) were entered into the second block, and finally the interaction term (Sexual Abuse by Sexual Concerns) was entered into the third block (Table 7)

In the third step of the regression analysis, the interaction term between severity of sexual abuse and sexual concerns symptoms explained a significant increase in variance in severity of sexual behavior problems as observed by therapists, $\Delta R^{2}=.08$, $F(1,125)=6.64, p<.05$. Thus, sexual concerns was a significant moderator of the relationship between sexual abuse and severity of sexual behavior problems. The 
unstandardized simple slope for youth with non-clinical sexual concerns was 0.94 , and the unstandardized simple slope for youth with clinical levels of sexual concerns was -0.5 (See Figure 1).

An ordinary least square regression was also run to determine gender differences for this interaction (Table 8). For these analyses age was again entered as a control into the first block using forward entry procedure. Gender, sexual concerns and severity of sexual abuse were entered into the second block. Finally the two interaction terms (Risk factor by SC, and Risk Factor by SC by Gender) were entered into the third block. Analyses revealed no significant three-way interaction for risk factors by SC symptoms by gender on severity of sexual behavior problems at the .05 significance level.

\section{Mediation Analyses}

To test for possible mediation effects of emotion dysregulation between risk factors and severity of sexual behavior problems Mediation Analyses were run following directions set forth by Baron and Kenny (1986). Baron and Kenny (1986) outlined four requirements that need to be met for mediation to occur. As a reminder, the four steps are outlined below:

It is necessary to show that the Independent Variable (Risk Factor) is correlated with the dependent variable (Severity of Sexual Behavior Problems). For this step the risk factor was used as the predictor variable in a regression equation and SBP as the criterion. Age and gender were entered as controls. Separate regressions were run for each risk factor. (Path c) 
It is necessary to show that the initial Independent Variable (Risk Factor) is correlated with the mediator (Emotion Dysregulation). Emotion dysregulation was used as the criterion variable in a regression equation and individual risk factors were entered as predictor variables. Age and gender were entered as controls. (Path a)

It is necessary to show that the mediator (Emotion Dysregulation) affects the outcome variable. Sexual Behavior Problems was used as the criterion variable in a regression equation and the Mediator (Emotion Dysregulation) was entered as the predictor while controlling for the Risk Factor. (Path b)

It is necessary to establish that the Mediator (Emotion Dysregulation) completely mediates the relationship between Risk factors and severity of SBP the effect of the IV on the DV was tested while controlling for the Mediator (path c'). For full mediation to be established, a drop in significance should be observed between the IV and DV when controlling for the Mediator. The effects in both step 3 and 4 were estimated in the same equation.

Figure 8: Mediation Model

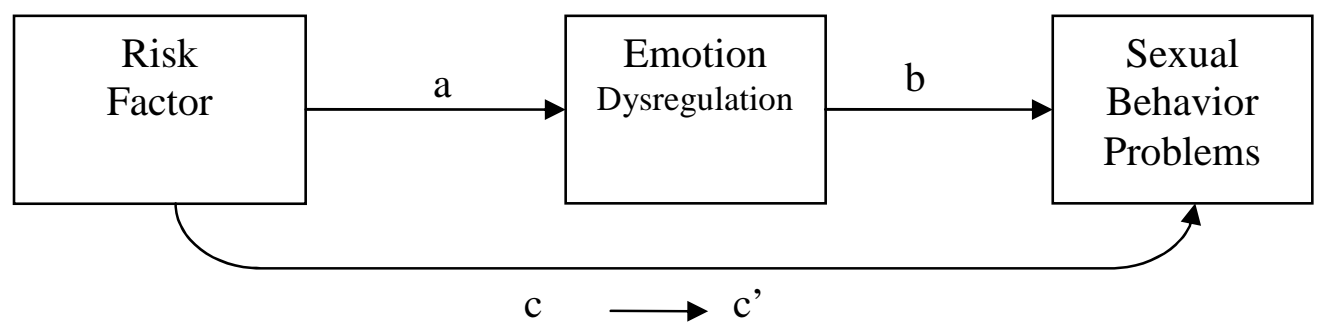


Below we have outlined the three models that need to be run to determine whether mediation is present.

$$
\begin{aligned}
& Y=\beta+\beta X+\varepsilon \\
& M e=\beta+\beta X+\varepsilon \\
& Y=\beta+\beta X+\beta M e+\varepsilon
\end{aligned}
$$

a. In Equation 1, there must be an overall treatment effect on the outcome (Y).

b. In Equation 2, there must be a treatment effect on the mediator (Me)

c. In Equation 3, there must be an effect of the mediator on the outcome, when

controlling for the treatment. In subsequent sections of this paper, the discussion focuses on how these basic steps are incorporated in the more complex moderated mediation analysis.

\section{Results of the Mediation Analyses}

Analyses reveal that for each risk factor tested, not one of the four steps necessary for establishing mediation (Baron \& Kenny, 1986) was supported. None of the required paths (a, b, c; Baron \& Kenny, 1986) were significant in any of the six models. Standardized coefficients and significance are presented for each path for each model in Figure 9-14.Non-signiifcane is depicted using (ns) notation on each path. 
Figure 9

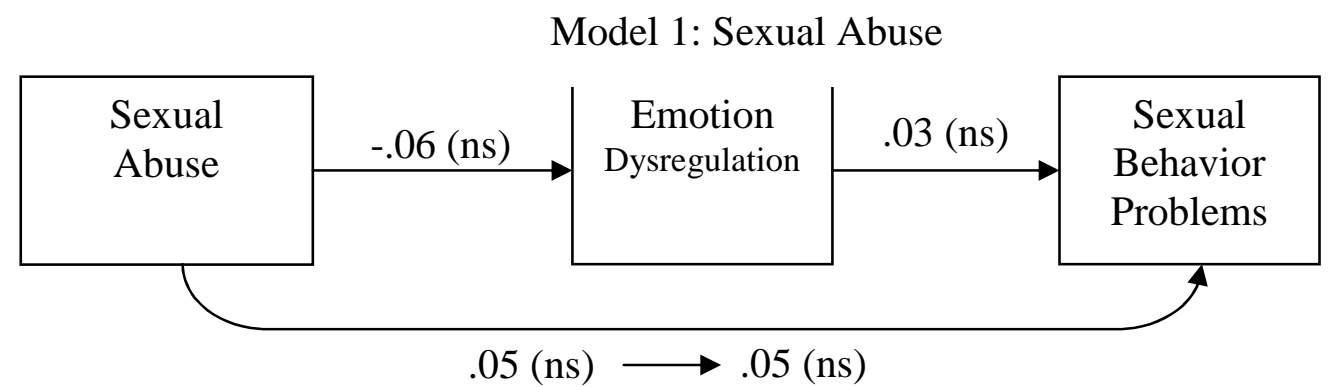

Figure 10

Model 2: Physical Abuse

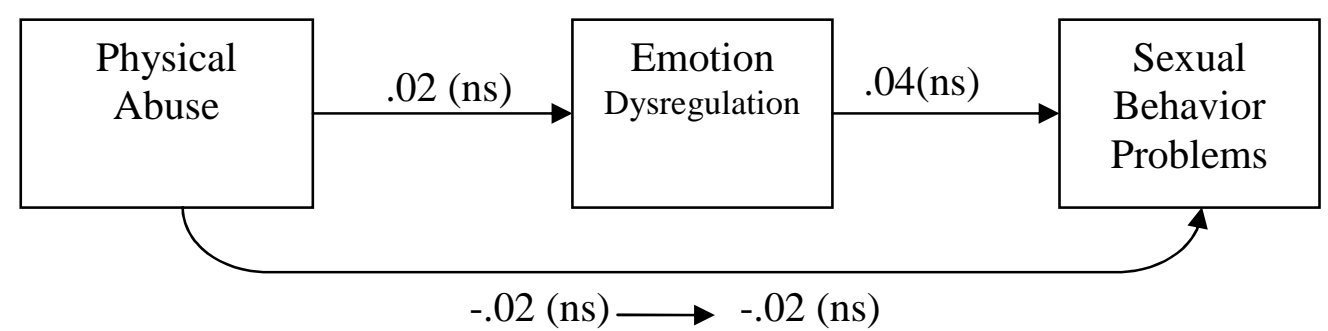

Figure 11

Model 3: Domestic Violence (Witness)

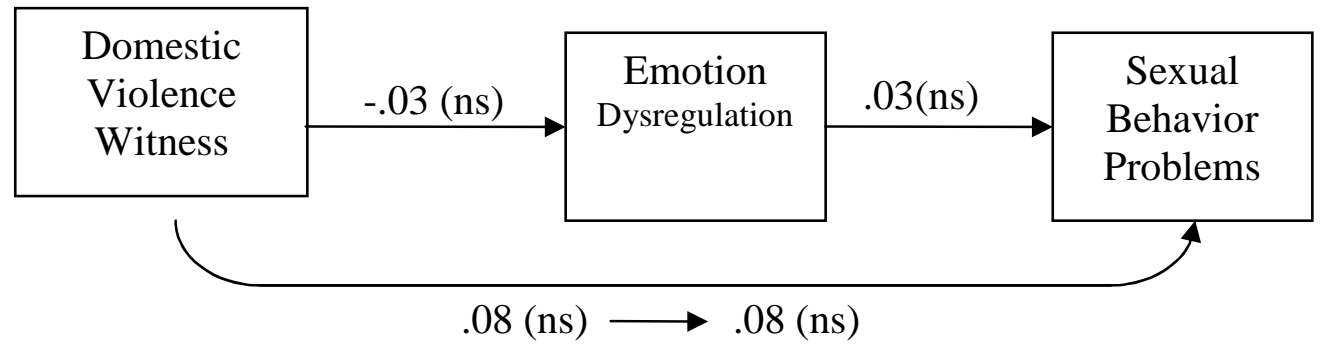


Figure 12

Model 4: Domestic Violence

(Victim)

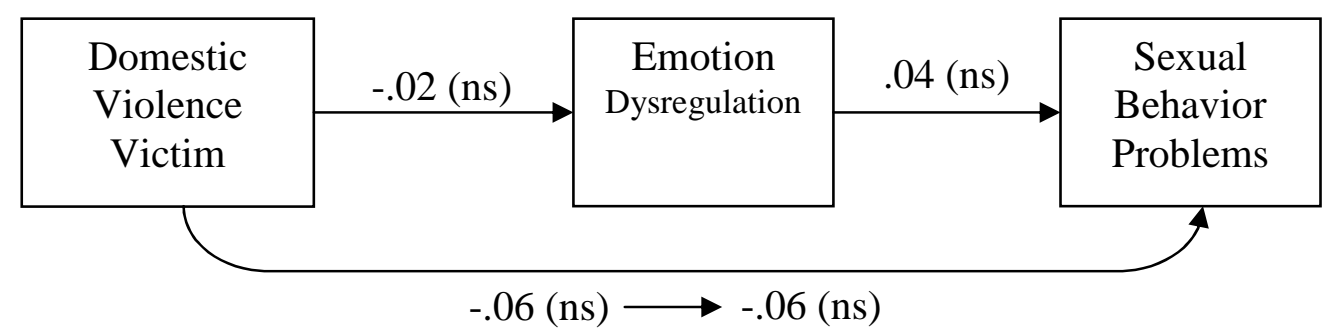

Figure $13 \quad$ Model 5: Community Violence

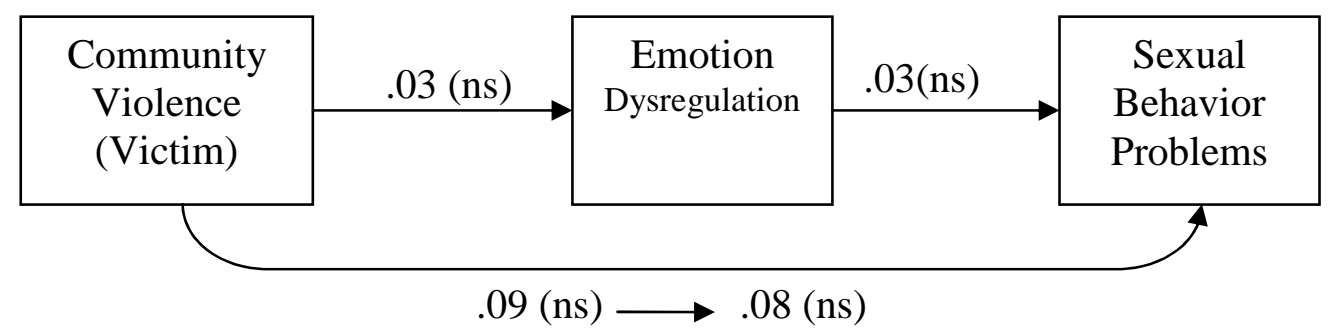

Figure 14

Model 6: Exposure to Sexual Violence

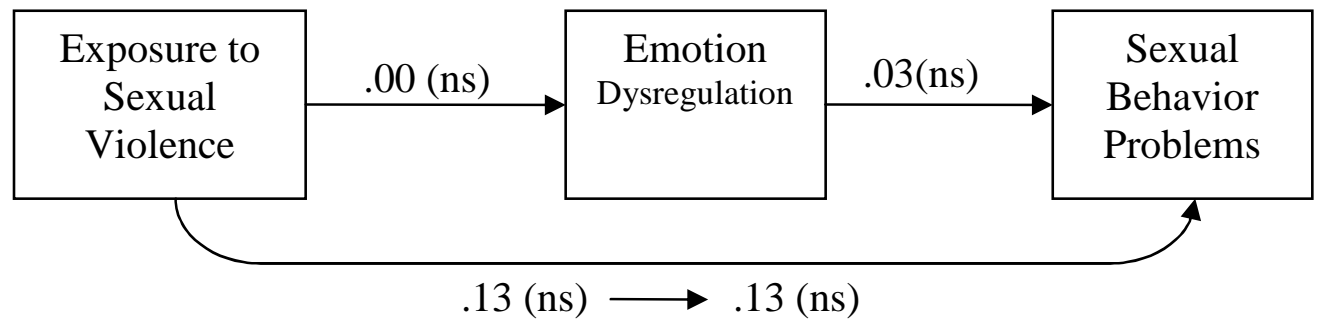

Moderated Mediation Analyses

As discussed in previous sections, moderated mediation is said to occur if the mediating process that is responsible for producing the effect of the treatment on the outcome depends on the value of a moderator variable, in this case, gender (Muller, Judd 
\& Yzerbyt, 2005). To be more specific, the mediating process (Emotion Dysregulation) that intervenes between the independent variable (Risk Factor) and the outcome variable (Severity of Sexual Behavior Problems) is different for participants based on Gender.

This definition of moderated mediation implies mediation of the relationship between the independent variable and outcome variable. What varies as a function of the moderator is not the magnitude of the overall treatment effect (Individual risk factors) on the outcome (SBPs), but the mediating process that produces it. As was discussed above, moderated mediation can occur in various ways.

Muller et al. (2005) described the prototypic case of moderated mediation, as one in which "there is an overall treatment effect and the magnitude of this effect does not depend on the moderator" (p. 856). They added that while the magnitude of this effect does not depend on the moderator, the potency of the mediating process does indeed depend on the moderator. In other words, based on these assumptions, either the effect of the independent variable on the mediator depends on the moderator, or the partial effect of the mediator in the outcome depends on the moderator, or both (Muller et al., 2005). In sum, moderated mediation implies that the indirect effect between the treatment and the outcome depends on the moderator.

Based on this approach, to demonstrate moderated mediation, Muller et al. (2005) argue that beyond the before mentioned three models, there are three added models that underlie moderated mediation:

$$
\begin{aligned}
& Y=\beta+\beta X+\beta M o+\beta X M o+\varepsilon \\
& M e=\beta+\beta X+\beta M o+\beta X M o+\varepsilon
\end{aligned}
$$




$$
Y=\beta+\beta X+\beta M e+\beta M o+\beta M e+\beta M e M o+\varepsilon
$$

a. Equation 4: This model allows the overall treatment effect of Equation 1 to be moderated by the moderator (Mo).

b. Equation 5: This model allows the treatment effect on the mediator (Me) in Equation 2 to be moderated

c. Equation 6: This model is a moderated version of Equation 3, in which the mediators partial effect on the outcome and the residual effect of the treatment on the outcome, controlling for the mediator, are allowed to be moderated.

Results of Moderated Mediation Analyses

Table 9a through 9f present the regression models that estimate Equations 4 through 6 with variables of interest. Six different analyses were run to explore moderated mediation with each risk factor. Presented in the table are the unstandardized coefficients (b) and their associated $t$ statistics. Focusing on the regressions model that estimates equation 4 (Table 9a-9f) across analyses it becomes clear that there is no significant overall effect of risk factors on the severity of Sexual behavior problems. There is also no significant moderation by gender. With regard to the regression model estimating equation 5 (Table 9a-9f), across analyses there is no significant effect of risk factor on emotion dysregulation and no significant interaction. Finally, with respect to the regression model estimating equation 6 (Table 9a-9f) across analyses, the residual effect of risk factors on SBPs is not moderated once the mediator is controlled. 
Table 3

Summary of Hierarchical Regression Analysis for Variables Predicting Sexual Behavior Problems.

\begin{tabular}{lccc}
\hline \multicolumn{1}{r}{ Variable } & $B$ & $S E$ & $\beta$ \\
\hline Step 1 & & & \\
Age & -.24 & .10 & $-.21^{*}$ \\
Gender & .88 & .47 & .16 \\
Step 2 & & & \\
Age & -.24 & .10 & $-.21^{*}$ \\
Gender & .86 & .48 & .15 \\
Sexual abuse & .25 & .27 & .08 \\
Physical abuse & .10 & .30 & .04 \\
Domestic violence (wit) & .30 & .30 & .12 \\
Domestic violence (vic.) & -.72 & .38 & -.25 \\
Community violence (vic.) & -.12 & .33 & -.05 \\
Community violence (sex violence) & .52 & .34 & .18 \\
\hline
\end{tabular}

Note. $\mathrm{R}^{2}=.07$ for Step 1 (ps<.05); $\Delta \mathrm{R}^{2}=.12$ for Step 2 .

$* p<.05$ 
Table 4

Moderation Sexual Abuse by PTS Symptoms

\begin{tabular}{lccc}
\hline \multicolumn{1}{c}{ Variable } & $\beta$ & $\mathrm{t}$ & Sig. \\
\hline Age & -.23 & -2.58 & $.01^{*}$ \\
Gender & .15 & 1.71 & .09 \\
Sexual abuse & .17 & 1.56 & .12 \\
PTS symptoms & .03 & .30 & .77 \\
Sexual abuse*PTS & -.12 & -1.08 & .28 \\
\hline Note: $*$ p $<.05$ & & &
\end{tabular}

Table 5

Moderation Physical Abuse by PTS Symptoms

\begin{tabular}{lccc}
\hline \multicolumn{1}{c}{ Variable } & $\beta$ & $\mathrm{t}$ & Sig. \\
\hline Age & -.21 & -2.36 & $.02^{*}$ \\
Gender & .15 & 1.74 & .09 \\
Physical abuse & .06 & .55 & .59 \\
PTS symptoms & .09 & .88 & .38 \\
Physical abuse*PTS & -.15 & -1.37 & .17 \\
\hline
\end{tabular}

Note: $* \mathrm{p}<.05$ 
Table 6a

Moderation Sexual Abuse by PTS Symptoms by Gender

\begin{tabular}{lccc}
\hline \multicolumn{1}{l}{ Variable } & $\beta$ & $\mathrm{t}$ & Sig. \\
\hline Age & -.22 & -2.31 & $.02 *$ \\
Gender & .16 & 1.75 & .08 \\
Sexual abuse & .16 & 1.44 & .15 \\
PTS symptoms & .02 & .16 & .87 \\
Sexual abuse*PTS & -.03 & -.13 & .90 \\
Sexual abuse*PTS*Gender & -.08 & -.42 & .68 \\
& & &
\end{tabular}

Table 7

Moderation Physical Abuse by PTS Symptoms by Gender

$\begin{array}{llll}\text { Variable } & \beta & \mathrm{t} & \text { Sig. }\end{array}$

\begin{tabular}{lccc}
\hline Age & -.20 & -2.22 & $.03 *$ \\
Gender & .16 & 1.76 & .08 \\
Physical abuse & .03 & .34 & .74 \\
PTS symptoms & .09 & .87 & .38 \\
Physical abuse*PTS & -.09 & -.46 & .65 \\
Physical abuse*PTS*Gender & -.06 & -.35 & .73 \\
\hline
\end{tabular}

Note: $* \mathrm{p}<.05$ 
Table 8

Moderation Domestic Violence (Witness) by PTS Symptoms by Gender

\begin{tabular}{lccc}
\multicolumn{1}{c}{ Variable } & $\beta$ & $\mathrm{t}$ & Sig. \\
\hline Age & -.21 & -2.40 & $.02^{*}$ \\
Gender & .16 & 1.75 & .08 \\
Domestic violence (witness) & .08 & .61 & .55 \\
PTS symptoms & .02 & .22 & .83 \\
Sexual abuse*PTS & .06 & .31 & .76 \\
Sexual abuse*PTS*Gender & -.10 & -.62 & .54 \\
\hline
\end{tabular}

Note: $* \mathrm{p}<.05$

Table 9

Moderation Domestic Violence (Victim) by PTS Symptoms by Gender

\begin{tabular}{lccc}
\multicolumn{1}{c}{ Variable } & $\beta$ & $\mathrm{t}$ & Sig. \\
\hline Age & -.19 & -2.09 & $.04^{*}$ \\
Gender & .16 & 1.78 & .08 \\
Domestic violence (victim) & -.10 & -.71 & .48 \\
PTS symptoms & .06 & .61 & .55 \\
$\begin{array}{l}\text { Domestic violence (victim)*PTS } \\
\text { Domestic violence }\end{array}$ & .04 & .21 & .83 \\
(victim)*PTS*Gender & -.03 & -.20 & .84
\end{tabular}

Note: $* \mathrm{p}<.05$ 
Table 10

Moderation Community Violence by PTS Symptoms by Gender

\begin{tabular}{lccc}
\multicolumn{1}{c}{ Variable } & $\beta$ & $\mathrm{t}$ & Sig. \\
\hline Age & -.22 & -2.46 & $.02 *$ \\
Gender & .16 & 1.73 & .09 \\
Community violence & .11 & .90 & .37 \\
PTS symptoms & .03 & .23 & .80 \\
Community violence*PTS & .01 & .02 & .98 \\
$\begin{array}{l}\text { Community } \\
\text { violence*PTS*Gender }\end{array}$ & -.08 & -.31 & .76 \\
\hline Note: $*$ p $<.05$ & & &
\end{tabular}

Table 11

Moderation Exposure to Sexual Violence by PTS Symptoms by Gender

\begin{tabular}{|c|c|c|c|}
\hline Variable & $\beta$ & $\mathrm{t}$ & Sig. \\
\hline Age & -.22 & -2.44 & $.02 *$ \\
\hline Gender & .18 & 1.88 & .06 \\
\hline Exposure to sexual violence & .13 & .87 & .39 \\
\hline PTS symptoms & -.04 & -.45 & .66 \\
\hline Exposure to sexual violence*PTS & .08 & .36 & .72 \\
\hline $\begin{array}{l}\text { Exposure to sexual } \\
\text { violence*PTS*Gender }\end{array}$ & -.06 & -.39 & .69 \\
\hline
\end{tabular}

Note: $* \mathrm{p}<.05$ 
Table 12

Moderation Sexual Abuse by Sexual Concerns (SC)

\begin{tabular}{lccc}
\hline \multicolumn{1}{c}{ Variable } & $\beta$ & $\mathrm{t}$ & Sig. \\
\hline Age & -.13 & -1.46 & .15 \\
Gender & .16 & 1.72 & .09 \\
Sexual abuse & .20 & 1.70 & .09 \\
SC symptoms & -.04 & -.37 & .71 \\
Sexual abuse*SC & -.24 & -1.99 & $.05^{*}$ \\
& & & \\
\hline Note: $* \mathrm{p}<.05$ & & &
\end{tabular}

Table 13

Moderation Sexual Abuse by Sexual Concerns (SC) by Gender

\begin{tabular}{lccc}
\multicolumn{1}{c}{ Variable } & $\beta$ & $\mathrm{t}$ & Sig. \\
\hline Age & -.24 & -2.66 & $.01^{*}$ \\
Gender & .20 & 2.20 & $.03^{*}$ \\
Sexual abuse & .31 & 2.73 & $.01 *$ \\
SC symptoms & .06 & .60 & .55 \\
Sexual abuse*SC & -.25 & -1.54 & .13 \\
Sexual abuse*SC*Gender & -.11 & -.72 & .47 \\
\end{tabular}

Note: $* \mathrm{p}<.05$ 
Table 14

Least Squares Regression Results for Moderated Mediation: Sexual Abuse

\begin{tabular}{|c|c|c|c|c|c|c|}
\hline \multirow[b]{2}{*}{ Predictors } & \multicolumn{4}{|c|}{$\begin{array}{c}\text { Criterion: } \\
\text { Emotion } \\
\text { Dysregulation (5) } \\
\end{array}$} & \multicolumn{2}{|c|}{$\frac{\text { Criterion: SBP }}{\underline{(6)}}$} \\
\hline & $b$ & $t$ & $b$ & $t$ & $b$ & $t$ \\
\hline IV: Sexual abuse & .70 & 1.40 & .61 & .71 & .63 & 1.24 \\
\hline Moderator: Gender & .70 & 1.45 & -.48 & -.57 & .75 & 1.53 \\
\hline Interaction Term: IV*Gender & -.72 & -1.25 & -.85 & -.86 & -.66 & -1.12 \\
\hline Mediator: Emotion dysregulation & & & & & .07 & .71 \\
\hline Interaction Term: Mediator*Gender & & & & & -.10 & -.89 \\
\hline
\end{tabular}

Table 15

Least Squares Regression Results for Moderated Mediation: Physical Abuse

\begin{tabular}{|c|c|c|c|c|c|c|}
\hline \multirow[b]{2}{*}{ Predictors } & \multicolumn{2}{|c|}{$\frac{\text { Criterion: SBP }}{\underline{(4)}}$} & \multicolumn{2}{|c|}{$\begin{array}{c}\text { Criterion: } \\
\text { Emotion } \\
\text { Dysregulation (5) }\end{array}$} & \multicolumn{2}{|c|}{$\frac{\text { Criterion: SBP }}{\underline{(6)}}$} \\
\hline & $b$ & $t$ & $b$ & $t$ & $b$ & $t$ \\
\hline IV: Physical Abuse & .23 & .51 & .29 & .39 & .21 & .45 \\
\hline Moderator: Gender & .94 & $\begin{array}{c}2.01 \\
*\end{array}$ & -.40 & -.51 & .93 & $1.98 *$ \\
\hline Interaction Term: IV*Gender & -.44 & -.83 & -.17 & -.19 & -.38 & -.71 \\
\hline Mediator: Emotion dysregulation & & & & & .05 & .53 \\
\hline Interaction Term: Mediator*Gender & & & & & -.08 & -.73 \\
\hline
\end{tabular}


Table 16

Least Squares Regression Results for Moderated Mediation: Domestic Violence (Witness)

\begin{tabular}{|c|c|c|c|c|c|c|}
\hline \multirow[b]{2}{*}{ Predictors } & \multicolumn{2}{|c|}{$\frac{\text { Criterion: SBP }}{\underline{(4)}}$} & \multicolumn{2}{|c|}{$\begin{array}{c}\text { Criterion: } \\
\text { Emotion } \\
\text { Dysregulation (5) }\end{array}$} & \multicolumn{2}{|c|}{$\frac{\text { Criterion: SBP }}{\underline{(6)}}$} \\
\hline & $b$ & $t$ & $b$ & $t$ & $b$ & $t$ \\
\hline IV: Domestic Violence (Witness) & .32 & .68 & -.84 & -1.03 & .43 & .90 \\
\hline Moderator: Gender & 61 & 1.23 & -.61 & -.70 & .70 & 1.39 \\
\hline Interaction Term: IV*Gender & -.29 & -.56 & 1.13 & 1.24 & -.40 & -.75 \\
\hline Mediator: Emotion dysregulation & & & & & .12 & 1.18 \\
\hline Interaction Term: Mediator*Gender & & & & & -.15 & -1.30 \\
\hline
\end{tabular}

Table 17.

Least Squares Regression Results for Moderated Mediation: Domestic Violence (Victim)

$\begin{array}{ccc}\text { Criterion: SBP } & \begin{array}{c}\text { Criterion: } \\ \text { Emotion } \\ \text { Dysregulation (5) }\end{array} & \frac{\text { Criterion: SBP }}{(6)}\end{array}$

\begin{tabular}{|c|c|c|c|c|c|c|}
\hline Predictors & $b$ & $t$ & $b$ & $t$ & $b$ & $T$ \\
\hline IV: Domestic Violence (Victim) & -.32 & -.63 & -.83 & -.98 & -.28 & -.54 \\
\hline Moderator: Gender & .69 & 1.42 & -.77 & -.91 & .78 & 1.57 \\
\hline Interaction Term: IV*Gender & .03 & .05 & 1.27 & 1.31 & -.00 & -.00 \\
\hline Mediator: Emotion dysregulation & & & & & .09 & .97 \\
\hline Interaction Term: Mediator*Gender & & & & & -.12 & -1.06 \\
\hline
\end{tabular}

Note. $* \mathrm{p}<.05 . * * \mathrm{p}<.01$ 
Table 18

Least Squares Regression Results for Moderated Mediation: Exposure to Community Violence

\begin{tabular}{|c|c|c|c|c|c|c|}
\hline \multirow[b]{2}{*}{ Predictors } & \multicolumn{2}{|c|}{$\frac{\text { Criterion: SBP }}{\underline{(4)}}$} & \multicolumn{2}{|c|}{$\begin{array}{c}\text { Criterion: } \\
\text { Emotion } \\
\text { Dysregulation (5) } \\
\end{array}$} & \multicolumn{2}{|c|}{$\frac{\text { Criterion: SBP }}{\underline{(6)}}$} \\
\hline & $b$ & $t$ & $b$ & $t$ & $b$ & $t$ \\
\hline IV: Community Violence (Victim) & .33 & .60 & .71 & .73 & .26 & .46 \\
\hline Moderator: Gender & .61 & 1.23 & -.90 & -1.04 & .71 & 1.39 \\
\hline Interaction Term: IV*Gender & -.27 & -.44 & -.45 & -.42 & -.19 & -.31 \\
\hline Mediator: Emotion dysregulation & & & & & .09 & .94 \\
\hline Interaction Term: Mediator*Gender & & & & & -.12 & -1.09 \\
\hline
\end{tabular}

Table 19

Least Squares Regression Results for Moderated Mediation: Exposure to Sexual Violence Criterion: SBP Criterion:
Emotion Dysregulation (5)

Criterion: SBP

(6)

\begin{tabular}{|c|c|c|c|c|c|c|}
\hline Predictors & $b$ & $t$ & $b$ & $t$ & $b$ & $T$ \\
\hline $\begin{array}{l}\text { IV: Community Violence (Sex } \\
\text { Crimes) }\end{array}$ & .40 & .93 & -.48 & -.63 & .43 & .99 \\
\hline Moderator: Gender & .69 & 1.41 & -.79 & -.92 & .79 & 1.59 \\
\hline Interaction Term: IV*Gender & -.13 & -.26 & .88 & .97 & -.15 & -.29 \\
\hline Mediator: Emotion dysregulation & & & & & .11 & 1.08 \\
\hline Interaction Term: Mediator*Gender & & & & & -.14 & -1.24 \\
\hline
\end{tabular}

Note. $* \mathrm{p}<.05 . * * \mathrm{p}<.01$. 


\section{CHAPTER FIVE}

\section{DISCUSSION}

The primary purpose of this study was to explore the relationship between diverse risk factors (sexual abuse, physical abuse, domestic violence, and exposure to community violence) and the severity of interpersonal sexual behavior problems (SBPs) among youth in substitute care. The child and adult psychopathology literatures have generally supported a positive relationship between the studied risk factors and sexual behavior problems and sexual offending. However, this study was the first attempt to examine such a diverse and relatively comprehensive set of risk factors together to understand the potentially unique variance of these variables in predicting severity of sexual behavior problems. Accordingly, it was hypothesized that in a vulnerable population with such extensive maltreatment histories, exposure to various risk factors would positively predict severity of sexual behavior problems.

Besides simply investigating the predictive power of various risk factors in terms of main effects, this study also sought to explore how co-occurring trauma symptoms (i.e., Post Traumatic Stress symptoms, Sexual Concerns) and gender may moderate this relationship. Finally, this study tested whether emotion dysregulation mediated any observed relationship between the risk factors and SBPs. The literature does not provide a consistent perspective on how trauma symptoms, gender, or emotional dysregulation 
may moderate or mediate the relationship between risk factors and sexual behavior problems. Consequently, although preliminary predictions were made, the majority of the analyses were exploratory in nature, and therefore results are discussed using the broader trauma and developmental psychopathology literature.

\section{Main Effects: Risk Factors}

By studying the potential impact of a diverse set of stressors on the severity of SBPs, the current study essentially employed what McMahon, Grant, Compas, et al. (2003) refer to as a Stressor Specific design (McMahon, Grant, Compas, Thurm \& Ey, 2003). A Stressor Specific design allows multiple stressors to statistically "compete" to determine which variables have the greatest impact on a psychopathology outcome, which in this study was SBPs. The goal of this design and other designs that study a wide range of variables (e.g., Outcome Specific and Stressor Outcome Specific) is to examine whether specific stressors and/or outcomes are related (e.g., sexual abuse history and sexual behavior problems). The results of this study did not find support for a direct relationship between any of the risk factors and the severity of childrens'sexual behavior problems.

It is important to note that while past research has frequently identified a relationship between risk factors and the presence of sexual behavior problems in children (Kendall Tackett, 1993), it is not uncommon to find non-significant relationships. For example Kendal-Tackett et al.'s (1993) classic review found that up to $45 \%$ of their sample of abused youth presented with no significant trauma or behavioral issues. Researchers have argued that youth may present as asymptomatic because the "the 
effect of the abuse [or trauma] could be masked, meaning that youth are suppressing feelings or they have not yet processed their experiences (Bal et al., 2004). Also, symptom manifestation may occur at a later time. Since the current study was crosssectional it is possible that severity of symptomatology may change over time.

A review of similar studies exploring the specificity of various risk factors in relation to sexual behavior problems in youths has also shown mixed findings. For example, Hernandez, Lodico, and DiClemente (1993) compared various forms of sexual abuse to physical abuse in relation to sexual aggression and found no specificity (sexual aggression was high for both types of abuse). On the other hand, Gale, Thompson, Moran and Sack, (1988) and Kolko, Moser, and Wekly (1988), using a stressor specific design to compare physical abuse and sexual abuse to sexual acting out, found sexual abuse to be specifically related to sexual behavior problems.

In their own review of the literature on the specificity hypothesis regarding stress and psychopathology in children, McMahon et al. (2003) conclude that several studies demonstrate a specific link between sexual abuse or physical abuse and sexual behavior problems. However, other studies show a link between these forms of abuse and a wide range of other outcomes, such as depression, eating disorders, and drinking problems. As a result, while individual studies may demonstrate a relationship between a specific stressor (e.g., sexual abuse) and a specific outcome (e.g., SBPs), these relationships frequently fail to re-emerge in other samples. In fact, different, albeit specific, relationships often emerge. One implication of these findings is that samples may vary widely in what makes them vulnerable to psychopathology and may also vary in their 
specific stressor-outcome links. For example, pre-adolescent boys who are physically abused may be particularly susceptible to becoming physically aggressive towards others, whereas other youth may not demonstrate such a link.

Therefore, aside from this study's limitations, the absence of a main effect relationship between the various stressors and the outcome, SBPs, in the current study may be due to the fact that main effects do not allow for the study of specific stressoroutcome links for specific sub-samples of youth. In order to study such effects, moderators and mediators must be examined, which was also done in this study and will be discussed below.

In the current sample, age was found to be the one and only main effect to predict severity of SBPs. Therapists reported older youths as presenting with less severe sexual behavior problems compared to younger children. This finding may appear to be counterintuitive, as adolescents might be presumed to present with more severe behaviors than their younger counterparts. However, prior research has demonstrated that sexual behavior problems tend to be more extreme among younger children, presumably because younger children need to engage in more serious behavior before they are considered a threat (Bonner et al., 1999; Friedrich et al., 2003; Friedrich et al., 2001). It is also possible that adolescents who committed more serious sexual offenses have been removed from foster care due to safety or legal reasons. Therefore, older youths who presented with more severe sexual offenses were not available for participation because they are now in the juvenile justice system. In turn, it can be argued that those older in the current study represent adolescents presenting with less serious behavior problems. 
Compared to females, males were found to present with significantly more severe sexual behavior problems. Past studies investigating outcomes of sexual abuse and other stressors have provided support for gender differences with respect to frequency and severity of sexual behavior problems among adolescents. The current finding is in accordance with data indicating gender differences in aggression (Archer, 2004). Generally, compared to females, males are considered to be more physically aggressive (Archer, 2004) and with respect to severity of sexual behavior problems past research indicates that males are significantly more likely to display victimizing behaviors (McClellan, McCurry, Ronnei, Adams, Storck, Eisner \& Smith, 1997). As such, it is not surprising, that males who present with sexual behavior problems will present with more violent behaviors compared to females, thus increasing their scores on the measure of severity of sexual behavior.

Supporting this explanation of the data, Ray and English (1995) found that boys and girls had similar mean number of victims but differed when it came to type of offenses. Female perpetrators were more likely to be involved in behaviors encompassing fondling and molestation, while males were more likely to be reported to child welfare agencies for rape, and other intrusive behaviors (Ray \& English, 1995)

\section{Interactions}

It was hypothesized that experiencing trauma symptoms (PTS) would moderate the relationship between individual risk factors and severity of SBPs. In other words, children who had experienced stressors and were also currently experiencing clinically significant trauma symptoms would present with more severe sexual behavior problems. 
Analyses revealed no significant relationship between individual risk factors and PTS symptoms and no significant direct relationships between independent variables and moderator were found for both males or females. Again, however, as McMahon et al (2003) suggest, what is largely missing from the research literature are studies examining relationships between specific stressors, outcomes, and moderators. It may be the case that PTS symptoms, which range from dissociation ("going away in my mind trying not to think" to hypervigilance (e.g. "feeling scared of men",) may be too general a moderator in a set of analyses exploring such specific stressors (e.g., witnessing community violence, sexual abuse) and such a specific outcome (e.g., SBPs). In order for this speculation to have merit, then the current study's examination of traumatic sexual concerns as a moderator of the relationship between sexual abuse and SBPs should have lead to significant results.

Findings did in fact support the moderating role of sexual concerns between sexual abuse and sexual behavior problems. It was hypothesized that children who presented with both sexual abuse and higher levels of sexual distress and preoccupation would present with more severe sexual behavior problems. Specifically it was predicted that children who were sexually abused and presented with significant sexual preoccupation and distress, would present with more serious sexual behavior problems. Interestingly however, the opposite occurred as analyses revealed that sexual concerns actually attenuated the relationship between sexual abuse and severity of sexual behaviors (see figure 1). At first glance this finding may appear to be counterintuitive in light of the available literature. Specifically, Noll and colleagues (2003) demonstrated 
that children with sexual distress and concerns tended to present with higher rates of sexually intrusive and inappropriate behaviors.

However, this study's findings appear to suggest that sexual concerns are actually protective against SBPs. How could trauma symptoms be protective against acting out behaviors such as SBPs? One possible explanation is that the sexual concerns scale on the Trauma Symptom Checklist for Children represents an internalizing response to sexual abuse trauma and SBPs represent a different response to trauma, one that is externalizing in nature. The psychodynamic literature would suggest that once a trauma has occurred, it "returns" (becomes relived) as an ongoing possibility for the individual. However, this possibility can either become relived through one's thoughts, as is the case with sexual concerns, or though one's behavior, as is the case with SBPs. Therefore, it may be that children who relive trauma by presenting with internalizing symptoms (Sexual Concerns) are less likely to present with externalizing symptoms (Sexual Behavior Problems) and vice versa.

The work of Jeffrey Gray and his neurobiological theory (1987) may offer empirical support for the sexual concerns moderation finding. Gray (1987) argued for the existence of two distinct and separate neurobiological systems. He distinguished between the Behavioral Activation System (BAS) and the Behavioral Inhibition System (BIS). Gray implicated the BAS in the manifestation of externalizing behaviors and the BIS in the production of anxious and depressive symptoms. Moreover, his neurobiological theory posited that the BAS and BIS systems "act in opposition to one another" (Gray, 1987). Findings in support of Gray's theory suggest that internalizing symptoms may 
have attenuating effects on the expression of externalizing disorders when present (Ollendick, 1999). Particularly related to conduct and oppositional defiant disorder, studies have found that anxiety may moderate the effects of conduct disturbance (Walker, et al., 1991), such that the presence of anxiety actually lowers the incidence of these externalizing disorders. In terms of the current study, it may be that the presentation of more serious sexual behavior problems suggests an activation of the behavioral activation system "without a concomitant increase in the activity of the behavioral inhibition system" (Ollendick et al., 1995). Gray suggests that this imbalance in the activation of the two separate systems results in increased rates and severity of externalizing behaviors, in this case sexual behavior problems.

\section{Mediating Role of Emotion Dysregulation}

Previous studies point to the mediating role of emotion dysregulation in the relation between direct victimization and subsequent behavior problems (Schwartz et al., 2000). Accordingly, it was hypothesized that youth with extensive and diverse maltreatment histories would present with more severe emotion regulation problems. Then, the current study hypothesized that emotion dysregulation would mediate the relation between different forms of direct and indirect victimization and subsequent sexually aggressive and intrusive behaviors. The hypothesized mediation was also predicted to depend on gender. Accordingly, each path in the mediation was investigated for possible moderation through gender.

Analyses revealed no significant associations between risk factors and emotion dysregulation for males or females in the sample. Moreover, emotion dysregulation did 
not predict sexual behavior problems nor mediate the relation between victimization and sexual behavior problems. There are several possible explanations for the emotion dysregulation findings here. First, this is the first known study to examine emotion dysregulation as a mediator in the context of SBPs, and it may be that emotion dysregulation is not involved in the developmental psychopathology of SBPs. Another, potentially more likely, reason for this study's findings relates to the lack of main effects relationships between the risk factors and SBPs (see above discussion). By convention (Kenny and Baron, 1987), the absence of a main effect relationship between risk factors and SBPs eliminated the possibility of uncovering mediation. And, the absence of main effects relationships may be due to the discussion above regarding the possible diversity of stressor-outcome links in the developmental psychopathology literature, or as discussed below, this study's limitations.

Finally, it is important to note that moderated mediation requires significant statistical power and is difficult to demonstrate (Baron \& Kenny, 1986; Muller et al., 2005). For example, Muller and colleagues (2005) and Baron and Kenny (1987) argued that all four steps must be met (see above) in order for mediation to occur, opening the door to Type II errors. And while there is not complete agreement on the need to demonstrate statistical significance at all four steps (James \& Brett, 1984; Kenny, Kashy \& Bolger, 1998; MacKinnon, Fairchild \& Fritz, 2007), moderated mediation requires the introduction of a moderator in the analysis, which requires additional power.

The current study applied the most stringent requirements for establishing mediation and moderated mediation (Muller et al., 2005). As was discussed in the results 
section, none of the paths (steps) were supported. Accordingly, it is not surprising that moderation of the overall mediation and individual steps was not significant. Moreover, the current study's relatively small sample size may have attributed to the lack of significant findings. Especially when investigating the moderating role of gender, the significant difference in sample size between males and females may have attributed to the non-significant interaction.

\section{Strengths and Limitations}

The current study investigated a population that has been relatively neglected in the developmental psychopathology literature. The current study suggests that children and adolescents in substitute care present with extensive and varied maltreatment histories, many of which are correlated with PTS symptoms. . The current study employed multiple sources (e.g. therapist, youth, DCFS file, and caregivers) to gather information on participants and to capture maltreatment history and current severity of sexual behavior problems. The use of multi-source data is a strength of the current study. It is only through the use of multiple data sources that the possibility of response bias can be mitigated. Further, this study used several well validated and commonly used measures, such as the Trauma Symptom Checklist- Children (TSCC), Survey of Children's Exposure to Violence (Richters \& Saltzman, 1990), and the Conflict Tactics Scale (Straus, Hamby, Boney-McCoy \& Sugarman, 1996). The use of validated tools provides confidence that the constructs under investigation are being accurately measured and allows for a better comparison with prior research.The current study suffered from various limitations that limit accurate interpretation and generalization of findings. 
Analyses did not account for various covariates which may have contributed to current results. Data was not available on medical history and cognitive capacity, both factors which have been linked with the outcome variable (SBPs). What's more, the current study did not take into account the impact of variations in substitute care histories might have impacted severity of sexual behavior problems. While data was available, it was extremely scarce and would have limited the power of statistical analyses. In light of the available research on the impact of length of stay and number of placements on adjustment and emotional functioning (Leon, 2008), future studies should take these possible covariates into account to better explain relationships between risk factors and outcomes.

\section{Limitations Related to Variables}

The outcome variable in the current study was severity of sexual behavior problems. As a variable, sexual behavior problems in youths is one that is considerably difficult to capture and properly define. The decision was made to use therapist's rating of youths sexual behavior problems. A standardized and reliable scale, the Children's Sexual Behavior Inventory (CSBI; Friedrich, 1997) was completed by parents and caregivers to assess children's presentation of sexual behavior problems and was available for use. However, the CSBI is normed and standardized solely for use with children between the age of two and twelve, which would have limited the sample to 50 participants. As such, the decision to use therapists' ratings of SBP was made to avoid loosing a significant proportion of the available data. As the CSBI is used to assess SBP 
in children between 2 and 12 years of age therapist rating and caregiver CSBI scores could not be combined for a clear description of the severity of sexual behavior problems.

Past research studies investigating sexual behavior problems in children have primarily relied on parents and caregivers as sources to determine severity of behavior problems (e.g. Merrick et al., 2008; Pithers \& Gray, 1998; Friedrich et al., 2004). Parents are generally assumed to have the most contact with children and as such should make for reliable sources with respect to the occurrence and severity of sexual behavior problems. Unfortunately, for the current study, the sample consisted of children who were in substitute care. At the time of data collection children's placement varied considerably, including hospitals, shelters, foster and group homes. Further, children varied with respect to the number of overall placements and duration of placements they had been involved with. Thus, since all participants had an assigned therapist who was familiar with individual cases it was decided to use treatments providers as the sole source for determining the severity of sexual behavior problems. The decision to use therapist ratings may be considered to be both a methodological limitation and strength of the current study. Therapists were asked to rate the most severe sexual behavior or offense demonstrated by youths. Based on the existing therapeutic relationship with participants and familiarity with individual DCFS case files, it was assumed that therapists would have a clear perspective on the severity of SBPs at the time of assessment and be more adept at providing an unbiased report regarding the actual motivation and seriousness of sexual behaviors (Johnson, 1998; 1999). Finally based on their training and experience in working with children who present with sexual behavior 
problems, it was expected that therapists would also be better able to differentiate between normal/healthy behaviors and actual behavior problems or sexual offenses.

Unfortunately, asking therapists to describe the severity of the behavior using a single item failed to completely capture the severity of behaviors and offenses. The use of a single item limits the amount of information that could be collected with respect to use of coercion, intimidation, and duration of problem behaviors. Future studies investigating the impact of multiple risk factors and possible mechanisms that predict sexual behavior problems should adopt more stringent methodological procedures to both define and capture sexual behavior problems in children and adolescents. Future research should collect information from multiple persons involved in youth's lives. Moreover, researchers should consider using qualitative data and analyses so as to better capture the complexity of sexual behavior problems across age groups and situations. Finally, youth were often asked about risk experiences long after their occurrence, because they were recruited to be in the study only after demonstrating SBPs, and not after experiencing risk. Accordingly, it can be argued that with time, the accuracy of the self-reported data may suffer due to recall bias (Tarren-Sweeney, 2008).

\section{Conclusion}

The current study and its findings have strong implications for future research with children in substitute care, presenting with sexual behavior problems. The present study had the opportunity to explore and examine multiple discrete influences on the development of sexual behavior problems in children. Findings indicated that the link between trauma exposure and victimization is not as straightforward and clear as may 
have been long assumed (Tarren-Sweeney, 2008). While the current study did not find support for the moderating role of PTS symptoms, results suggest that increased levels of anxiety and sexual preoccupation may work to attenuate the impact of sexual abuse on the development of sexual behavior problems. Future studies will need to address methodological limitations to further explore the relationship between trauma, trauma symptoms and the development of sexual behavior problems in high risk populations. 


\section{REFERENCES}

Adams, J., McClellan, J., Douglass, D., McCurry, C., \& Storck, M. (1995). Sexually inappropriate behaviors in seriously mentally ill children and adolescents. Child Abuse \& Neglect, 19, 555-568.

Araji, S. K., (1997). Sexually aggressive children: Coming to understand them. Thousand Oaks, CA: Sage.

Archer, J. (2004). Sex differences in aggression in real-world settings: a meta-analytic review. Review of General Psychology, 8, 291-322.

Baker, A. J. L., Gries, L., Schneiderman, M., Parker, R., Archer, \& Friedrich,W. N. (in press). Children with problematic sexualized behaviors in the child welfare system. Child Welfare.

Baker, A., J. L., Schneiderman, M., \& Parker, R. (2001). A survey of problematic sexualized behaviors of children in the New York city child welfare system: estimates of problem, impact on services, and need for training. Journal of Child Sexual Abuse, 10, 67-81.

Bandura, A. (1986). Social foundations of thought and action: A social cognitive theory. Englewood Cliffs, NJ: Prentice Hall.

Barbaree, H., Marshall,W.,\& McCormick, J. (1998). The development of deviant sexual behaviour among adolescents and its implications for prevention and treatment. Irish Journal of Psychology, 19, 1-31.

Baron, R. M., \& Kenny, D. A. (1986). The moderator-mediator variable distinction in social psychological research: Conceptual, strategic and statistical considerations. Journal of Personality and Social Psychology, 51, 1173-1182.

Becker, J. V. (1998). What we know about the characteristics and treatment of adolescents who have committed sexual offences. Child Maltreatment, 3, 317329.

Bell, C., \& Jenkins, E. (1991). Traumatic stress and children in danger. Journal of Health Care for the Poor and Undeserved, 2, 175-188 
Benedict, M.I., Zuravin, S., Somerfield, M., \& Brandt, D. (1996). The reported health and functioning of children maltreated while in family foster care. Child Abuse \& Neglect, 20, 561-571.

Berliner, L., Manois, O., and Monastersky, C. (1986). Child sexual behavior disturbance: An assessment and treatment model. Seattle: Sexual Assault Center and University of Washington.

Bowlby, J. (1982). Attachment and loss, (Vol. 3). New York: Basic Books.

Bonner, B.,Walker, C. E., \& Berliner, L. (2000). Final report. Children with sexual behavior problems: Assessment and treatment. Grant No. 90-CA-1469. Washington, DC: National Clearinghouse on Child Abuse and Neglect.

Bonner, B. L., Walker, C. E., \& Berliner, L. (1999).Children with sexual behavior problems: Assessment and treatment (Final report, Grant No. 90-CA-1469). Washington, DC: Department of Health and Human Services, Administration of Children, Youth, and Families.

Briere, J. (1996). Trauma symptom checklist for children (TSCC) professional manual. Odessa, FL: Psychological Assessment Resources.

Briere, J. (1992). Methodological issues in the study of sexual abuse effects. Journal of Consulting and Clinical Psychology, 6, 196-203.

Briere, J., \& Elliot, D. (1994). Immediate and long-term impacts of child sexual abuse. Sexual Abuse of Children, 4, 54-69.

Buka, S. L., Stichick, T. L., Birdthistle, I., \& Earls, F. J. (2001). Youth exposure to violence: Prevalence, risks, and consequences. American Journal of Orthopsychiatry, 71, 298-310.

Burton, D. (2000). Were adolescent sexual offenders children with sexual behavior problems? Sexual Abuse: A Journal of Research and Treatment, 12(1), 37-48.

Caputo, A. A., Frick, P. J., \& Brodsky, S. L. (1999). Family violence and juvenile sex offending: The potential mediating role of psychopathic traits and negative attitudes toward women. Criminal Justice \& Behavior, 26, 338-356.

Chaffin, M., Berliner, L., Block, R., Johnson, T.C., Friedrich, W., Louis, D., et al. (2006). Report of the association for the treatment of sexual abusers task force on children with sexual behavior problems. Child Maltreatment, 13. 
Cicchetti, D., Toth, S. L., \& Maughan, A. (2000). An ecological-transactional model of child maltreatment. In A. Sameroff \& M. Lewis (Eds.), Handbook of developmental psychopathology ( $2^{\text {nd }}$ ed., pp. 689-722). Dordrecht, Netherlands: Kluwer Academic publishers.

Cicchetti, D., \& Toth, S. (1995). A developmental psychopathology perspective on child abuse and neglect. Journal of the American Academy of Child and Adolescent Psychiatry, 34, 541-565.

Cummings, E. M., Hennessy, K. D., Rabideau, G. J., \& Cicchettim D. (1994). Responses of physically abused boys to interadult anger. Development and Psychopathology, $6,31-41$.

Clemmons, J.C., Walsh, K., DiLillo, D., \& Messman-Moore, T.L. (2007). Unique and combined contributions of multiple child abuse types and abuse severity to adult trauma symptomatology. Child Maltreatment, 12, 172-181.

Cole, P., M., Martin, S., \& Dennis, T. (2004). Emotion regulation as a scientific construct: methodological challenges and directions for child development research. Child Development, 75, 317-333.

Cicchetti, D., \& Toth, S. (1995). A developmental psychopathology perspective on child abuse and neglect. Journal of the American Academy of Child and Adolescent Psychiatry, 34, 541-565.

Cummings, E. M., Hennessy, K. D., Rabideau, G. J., \& Cicchettim D. (1994). Responses of physically abused boys to interadult anger. Development and Psychopathology, 6, 31-41.

Durlak, J.A. (1998). Common risk and protective factors in successful prevention programs. American Journal of Orthopsychiatry, 68, 512-520.

Edlynn, Emily Sarah (2007) The impact of violence exposure on sexually abusive behavior in types of adolescent sex offenders. Ph.D. dissertation, Loyola University Chicago, United States -- Illinois. Retrieved October 10, 2008, from Dissertations \& Theses @ Loyola University Chicago database. (Publication No. AAT 3280687).

Fehrenbach, P. A., Smith, W., Monastersky, C., \& Deisher, R. W. (1986). Adolescent sexual offenders: offender and offense characteristics. American Journal of Orthopsychiatry, 56(2), 225-233.

Finkelhor, D., \& Browne, A. (1985). The traumatic impact of child sexual abuse: A conceptualization. American Journal of Orthopsychiatry, 55(4) 
Fitzpatrick, K., \& Boldizar, J. P. (1993). The prevalence and consequences of exposure to violence among African-American youth. Journal of the Academy of Child and Adolescent Psychiatry, 32, 424-430.

Friedrich, W. N. \& Luecke, W. J. (1988). Young school-age sexually aggressive children. Professional Psychology, 19, 155-164.

Friedrich, W. N., Fisher, J., Dittner, C., Acton, R., Berliner, L., Butler, J., Damon, L., Davies, W. H., Gray, A., Wright, J. (2001). Child sexual Behavior Inventory: Normative, psychiatric and sexual abuse comparison. Child Maltreatment, 6, 3749.

Friedrich, W. N., Grambsch, P., Broughton, D., Kuiper, J., \&Beilke, R. L. (1991). Normative sexual behavior in children, Pediatrics, 88 , 456-464.

Friedrich, W.N., Grambsch, P., Damon, L. Hewitt, S., Koverola, C., Lange, R., Wolfe, V., \& Broughton, D. (1992). The child sexual behavior inventory: Normative and clinical findings. Psychological Assessment, 4, 303-311.

Friedrich, W. N. (1995). The clinical use of the Child Sexual Behavior Inventory: Frequently asked questions. The APSAC Advisor, 8, 1-20.

Friedrich, W. N., Fisher, J., Broughton, D., Houston, M., \& Shafran, C. (1998). Normative sexual behavior in children: A contemporary sample. Pediatrics, 101, $1-8$.

Friedrich, W. N. (1997). Child sexual behavior inventory: Professional manual. Odessa, FL: Psychological Assessment Resources.

Friedrich, W. N., Davies, W., Fehrer, E., \& Wright, J. (2003). Sexual behavior problems in preteen children: Developmental, ecological, and behavioral correlates. Annals of the New York academy of sciences, 989, 95-104.

Friedrich, W. N., Baker, A. J. L., Parker, R., Schneiderman, M., Gries, L., \& Archer, M. (2005). Youth with problematic sexualized behaviors in the child welfare system: A one- year longitudinal study. Sexual Abuse: A Journal of Research and Treatment. 17, 391- 406.

Gale, J., Thompson, R. J., Moran, T., \& Sack, W. H. (1988). Sexual abuse in young children: Its clinical presentation and characteristic patterns. Child Abuse and Neglect, 12, 163-170.

Gorman-Smith, D., \& Tolan, P. (1998). The role of exposure to community violence and developmental problems among inner-city youth. Development of Psychopathology, 10, 101-116. 
Grant, K. E., Compas, B. E., Hurm, A. E., McMahon, S.D., Gipson, P. Y., Campbell, A. J., Krochock, K., \& Westerholm, R. I. (2006). Stressors and child and adolescent psychopathology: Evidence of moderating and mediating effects. Clinical Psychology Review, 26, 257-283.

Gray, A., Pithers, W., Busconi, A., \& Houchens, P. (1999). Developmental and etiological characteristics of children with sexual behavior problems: Treatment implications. Child Abuse \& Neglect, 23(6), 601-621.

Gray, A., Busconi, A., Houchens, P., \& Pithers, W. D. (1997). Children with sexual behavior problems and their caregivers: Demographics, functioning, and clinical patterns. Sexual Abuse: A Journal of Research and Treatment, 9, 267-290.

Hernandez, J., Lodico, M., \& DiClemente, R. (1993). The effects of child abuse and race on risk-taking in male adolescents. Journal of the National Medical Association, $85,593-597$.

Holmbeck, G. N. (1997). Toward terminological, conceptual, and statistical clarity in the study of mediators and moderators: Examples from the child-clinical and pediatric psychology literatures. Journal of Consulting and Clinical Psychology, 65(4), 599-610.

Howard, D.E., Cross, S.J., Li, X., \& Huang, W. (1999). Parent-youth concordance regarding violence exposure: Relationship to youth psychological functioning. Journal of Adolescent Health, 25, 396-406.

Howells, K., \& Day, A. (2004). Affect, emotions and sex offending. Psychology, Crime \& Law, 10, 179-195.

Hughes, H.M., Parkinson, D., \& Vargo, M. (1989). Witnessing spousal abuse and experiencing physical abuse: A "double whammy"? Journal of Family Violence, 4, 197-209.

Jenkins, E. J., \& Bell, C. G. (1994). Posttraumatic stress disorder and violence among inner-city high school students. In S. Friedman (Ed.), Anxiety disorders in African Americans (pp. 76-88). New York: Springer.

Johnson, T. C. (1998). Children who molest. In W. Marshall, \& Y. Fernandez (Ed.), Sourcebook of treatment programs for sexual offenders (pp. 337-352). New York, NY: Plenum Press.

Johnson, T. C. (1999). Understanding your child's sexual behavior: What's natural and healthy? Oakland CA: Harbinger Publications, Inc.

Kaufman, J., \& Cicchetti, D. (1989). Effects of maltreatment on school-age children's socioemotional development: Assessment in a day-camp setting, Developmental Psychology, 25, 516-524. 
Kendall-Tackett, K. A., Williams, L. M., \& Finkelhor, D. (1993). Impact of sexual abuse on children: A review and synthesis of recent empirical studies. Psychological Bulletin, 113, 164-180.

Kolko, D.J., Moser, J., \& Weldy, S.R. (1988). Behavioral/ emotional indicators of sexual abused in child psychiatric inpatient: A controlled comparison with physical abuse. Child Abuse and Neglect, 12, 529-541.

Leon, S.C., Ragsdale, B., Miller, S.A., \& Spaccarelli, S. (2008) Trauma resilience among youth in substitute care demonstrating sexual behavior problems. Child Abuse and Neglect, 32, 67-81.

Letourneau, E. Schoenwald, S., \& Sheidow, A. (2004). Children and adolescents with sexual behavior problems. Child Maltreatment, 9(1), 49-61.

Lewis, D.O., Shanok, S.S., \& Pincus, J.H. (1981). Juvenile male sexual assaulters: Psychiatric, neurological, psychoeducational, and abuse factors. In D.O. Lewis (Ed.), Vulnerabilitiesto Delinquency (pp. 89-105). Jamaica, NY: Spectrum Publications.

Lodico, M., Gruber, E., \& DiClemente, R.J. (1996). Childhood sexual abuse and coercive sex among school-based adolescents in a midwestern state. Journal of Adolescent Health, 18, 211-217.

Margoling, G., \& Gordis, E.B. (2000). The effects of family and community violence on children. Annual Review of Psychology, 51, 445-479.

Mathews, R., Hunter, J., \& Vuz, J. (1997) Juvenile female sexual offenders: Clinical characteristics and treatment issues. Sexual Abuse: A Journal of Research and Treatment, 9, 187-200.

McClellan, J., McCurry, C., Ronnei, M., Adams, J., Storck, M., Eisner, A., \& Smith, C. (1997). Relationship between sexual abuse, gender, and sexually inappropriate behaviors in seriously mentally ill youths. American Academy of Child and Adolescent Pschiatry.36, 959-965.

McMackin, R., Morissey, C., Newman, E., Erwin, B., \& Daly, M. (1998). Perpetrator and victim: Understanding and managing the traumatized young offender. Corrections Management Quarterly, 2, 35-44.

McMahon, S.D., Grant, K.E., Compas, B.E., Thurm, A.E, \& Ey, S. (2003). Stress and psychopathology in children and adolescents: is there evidence of specificity? Journal of Child Psychology \& Psychiatry \& Allied Disciplines, 44, 107-133. 
Merrick, M. T., Litrownik, A. J, Everson, M. D., \& Cox, C. E. (2008). Beyond sexual abuse: The impact of maltreatment experiences on sexualized behaviors. Child Maltreatment, 13(2), 122-132.

Millham, S., Bullock, R., Hosie, K., \& Haak, M. (1986). Lost in care. London: Gower.

Muller, D., Judd, C. M., \& Yzerbyt, V. Y. (2005). When moderation is mediated and mediation is moderated. Journal of Personality and Social Psychology, 89 ,852863.

Newton, R.R., Litrownik, A.J., \& Landsverk, J.A. (2000). Children and youth in foster care: Disentangling the relationship between problem behaviors and number of placements. Child Abuse \& Neglect, 24, 1363-1374.

Nottelmann, E., \& Jensen, P. (1995). Comorbidity of disorders in children and adolescents: Developmental perspectives. In T. H. Ollendick \& R. J. Prinz (Eds.), Advances in clinical child psychology (Vol. 17, pp. 109-155). New York: Plenum Press.

Ollendick, T., Seligman, \& L., Butcher, T. (1999). Does anxiety mitigate the behavioral expression of severe conduct disorder in delinquent youths? Journal of Anxiety Disorders, 13, 565-574.

Parrott, D. J., \& Zaichner, A. (2003). Effects of trait anger and negative attitudes towards women on physical assault in dating relationships. Journal of Family Violence, 18, 301-307.

Phipps-Yonas, S., Yonas, A., Turner, M., Kauper, M, (1993). Sexuality in early childhood. University of Minnesota Center for Urban and Regional Affairs Reports, 23, 1-5.

Pithers, W., \& Gray, A. (1998). The other half of the story: Children with sexual behavior problems. Psychology, Public Policy, and Law. 4, 200-217.

Pomeroy, J. C., Behar, D., \& Stewart, M. A. (1981). Abnormal sexual behaviour in prepubescent children. The British Journal of Psychiatry, 138, 119-125.

Preacher, K., Rucker, D., \& Hayes, A. (2007). Addressing moderated mediation hypotheses: Theory, methods, and prescriptions. Multivariate Behavioral Research, 42, 185-227.

Richters, J. E., \& Saltzman, W. (1990). Survey of children's exposure to community violence (self-report version). Rockville, MD: NIMH.

Rutter, M. (1971). Normal Psychosexual Development. Child Psychology and Psychiatry, 11, 259-283. 
Rosenthal, B. S. (2000). Exposure to community violence in adolescence: Trauma symptoms. Adolescence, 3, 271-284.

Ruchkin, V., Henrich, C., Jones, S., Vermeiren, R., \& Schwab-Stone. (2007). Violence exposure and psychopathology in urban youth: the mediating role of posttraumatic stress. Journal of Abnormal Child Psychology, 35, 578-594.

Ryan, G. \& Lane, S. (1997). Juvenile sexual offending: Causes, consequences, and correction. San Francisco, CA: Jossey-Bass.

Sandnabba, N. K., Santilla, P., Wannaes, M., \& Krook, K. (2003). Age and gender specific sexual behaviors in children. Child Abuse and Neglect, 27, 579-605.

Schwartz, B.K., Cavanaughm D., Pimental, A., \& Prentky, R. (2006). Descriptive study of precursors to sex offending among 813 boys and girls: Antecedent life

Schwartz, D., \& Proctor, L. (2000). Community violence exposure and children's social adjustment in the school peer group: the mediating role of emotion regulation and social cognition. Journal of Consulting and Clinical Psychology, 68, 670-683.

Shields, A., \& Cicchetti, D. (1998). Reactive aggression among children: the contributions of attention and emotion dysregulation. Journal of Clinical Child Psychology, 27, 381-395.

Silovsky, J. F., Niec, L., Bard, D., \& Hecht, D. (2007). Treatment for preschool children with interpersonal sexual behavior problems: A pilot study. Journal of Clinical Child and Adolescent Psychology, 36, 378-391.

Silovsky, J., \& Niec, L. (2002). Characteristics of young children with sexual behavior problems: A pilot study. Child Maltreatment, 7(3), 187-197.

Silovsky, J. F. \& Bonner, B. L. (2003). Children with sexual behavior problems. In T. H. Ollendick \& C. S. Schroeder (Eds.), Encyclopedia of clinical child and pediatric psychology (pp. 589-591). New York: Kulwer.

Silovsky, J. F., Letourneau, E. J. (2008). Introduction to special issue on children with sexual behavior problems. Child Maltreatment, 13, 107-109.

Smith, W.R. (1988). Delinquency and abuse among juvenile sexual offenders. Journal of Interpersonal Violence, 3, 400-413.

Snyder, H. N. (2000). Sexual assault of young children as reported to law enforcement: Victim, incident, and offender characteristics. Washington, D.C Bureau of Justice Statistics, U.S. Department of Justice.

Social and Rehabilitation Services (1995, July). Vermont child abuse and neglect. Waterbury, VT: Author. 
Spaccarelli, S. (2002) Children with sexual behavior problems: longitudinal study (CLS Project). Second Progress Report, 8.1.2002.

Straus, M.A., Hamby, S.L., Boney-McCoy, S., \& Sugarman, D.B. (1996). The revised Conflict Tactics Scale (CTS-2): Development and preliminary data. Journal of Family Issues, 17, 283-316.

Tarren-Sweeney, M., Hazell, P., \& Carr, V. (2004). Are foster parents reliable informants of children's behavior problems? Child: Care, Health \& Development, 30, 167175.

Tarren-Sweeney, M. (2008). Predictors of problematic sexual behavior among children with complex maltreatment histories. Child Maltreatment, 13, 182-198.

Thompson, R. A. (1994). Emotional regulation: a theme in search for definition. In N. A. Fox, The development of emotion regulation: behavioral and biological consideration. Monographs of the Society for Research in Child Development, 59, $25-52$.

Van der Kolk, B. (2005) Developmental trauma disorder. Psychiatric Annals, 401-408.

Vick, J., McRoy, R., \& Matthews, B. (2002). Young female sex offenders: Assessment and treatment issues. Journal of Child Sexual Abuse, 11, 1-24.

Vizard, E., Hickey, N., \& McCrory, E. (2007). Developmental trajectories associated with juvenile sexually abusive behaviour and emerging severe personality disorder in childhood: 3 year study. The British Journal of Psychiatry, 190 (49).

Weinrott, M. R. (1996). Sexual aggression: A critical review. Boulder: Center for the Study and Prevention of Violence, Institute for Behavioral Sciences, University of Colorado, Boulder.

World Health Organization. (2002). The world health report-2002. Geneva: Author. 


\section{VITA}

Christopher Zaddach is entering his fourth year of study in the Clinical Psychology Ph.D. program at Loyola University Chicago. His current research interest includes investigation of risk/resiliency models in vulnerable populations including children, adolescence, and emerging adulthood and application of research to inform appropriate prevention and intervention. 